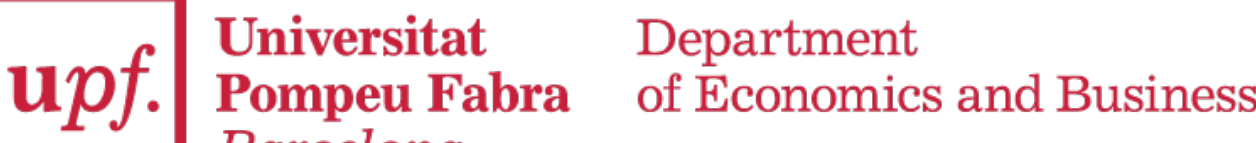 Barcelona
}

\author{
Economic Working Paper \\ Series Working Paper No. 1712
}

\section{Security Design in non-exclusive markets with asymmetric information}

Vladimir Asriyan

Victoria Vanasco

November 2019 


\title{
Security Design in Non-Exclusive Markets with Asymmetric Information
}

\author{
Vladimir Asriyan and Victoria Vanasco*
}

November, 2019

\begin{abstract}
We revisit the classic problem of a seller (e.g. firm) who is privately informed about her asset and needs to raise funds from uninformed buyers (e.g. investors) by issuing securities backed by her asset cash flows. In our setting, buyers post menus of contracts to screen the seller, but the seller cannot commit to accept contracts from only one buyer, i.e., markets are non-exclusive. We show that an equilibrium of this screening game always exists, it is unique and features semi-pooling allocations for a wide range of parameters. In equilibrium, the seller tranches her asset cash flows into a debt security (senior tranche) and a levered-equity security (junior tranche). Whereas the seller of a high quality asset only issues her senior tranche, the seller of a low quality asset issues both tranches but to distinct buyers. Consistent with this, whereas the senior tranche is priced at pooling valuation, the junior tranche is priced at low valuation. Our theory's positive predictions are consistent with recent empirical evidence on issuance and pricing of mortgage-backed securities, and we analyze its normative implications within the context of recent reforms aimed at enhancing transparency of financial markets.
\end{abstract}

Keywords. Adverse Selection; Security Design; Non-Exclusivity; Tranching; Liquidity; Securitization; Transparency; Opacity; Complexity; Market Design; Regulation.

\footnotetext{
*Asriyan: CREi, UPF, Barcelona GSE and CEPR; vasriyan@crei.cat. Vanasco: CREi, UPF and Barcelona GSE; vvanasco@crei.cat. We thank Bruno Biais, Peter DeMarzo, Jason Roderick Donaldson, Denis Gromb, Alberto Martin, Giorgia Piacentino, and seminar/conference participants at CREI, UPF, SED Meetings in Mexico City and ESSFM in Gerzensee for helpful feedback and suggestions.
} 


\section{Introduction}

The question of how markets function in the presence of information asymmetries has been central to economics since the seminal work of Akerlof (1970), who showed that information asymmetries between sellers and buyers can give rise to equilibrium multiplicity and market failures. In the study of asset markets, a large literature followed that explored the role of security design, i.e. the ability of sellers to optimally design and issue securities backed by asset cash flows, in ameliorating such information frictions. From it, we learned that by retaining exposure to an asset's cash flows a seller may be able to credibly convey to buyers information about her asset quality (e.g. Leland and Pyle (1977); DeMarzo and Duffie (1999)); and that standard debt emerges as the optimal security design since it minimizes the distortions due to adverse selection (e.g. Nachman and Noe (1994); DeMarzo and Duffie (1999); Biais and Mariotti (2005); DeMarzo (2005); Daley, Green, and Vanasco (2016)). This literature, however, has implicitly assumed that there is exclusivity in contracting, i.e. that a buyer of a security can ensure that its seller does not engage in financial trade with other agents in the market. In many settings of interest, however, exclusivity may be difficult to enforce.

Exclusive contracting effectively requires that the seller is able to commit to trade with only one buyer, even if gains from trade arise with other buyers; or that the buyers are able to observe and contract upon the entire set of the seller's trades. In the context of modern financial markets, however, these requirements are unlikely to be fulfilled: there is little information about agents' trades, and the complexity of certain financial products makes it difficult for potential buyers to understand a seller's overall position and resulting risk-exposures. This has been of particular concern to policymakers in the US, who are in the process of implementing policies aimed at enhancing exclusivity in markets for securitized products (see more details below). Moreover, lack of exclusivity is not only of concern for securitized products, which are traded in opaque over-the-counter markets, but also for credit markets more generally: e.g. credit card or peer-to-peer loans are not made public in most countries.

Motivated by these observations, we revisit the classic problem of a seller who is privately informed about her asset and raises funds from uninformed buyers by issuing securities backed by her asset cash flows. We consider a screening game, where buyers post menus of contracts (securities and prices) to be accepted by the seller, but where the seller cannot commit to trade with only one buyer, i.e. markets are non-exclusive. We use our framework to study the implications of non-exclusivity for equilibrium allocations, as characterized by issued securities and their prices, which we show are consistent with recent empirical evidence from markets for mortgage-backed securities. We then investigate the theory's normative implications, which we relate to policy discussions and proposed reforms in the aftermath of the global financial crisis. 
Our setup is as follows. There is a risk-neutral seller endowed with an asset that pays random cash flow, $X$, in the future; and, there is a large number of competitive, risk-neutral, deep-pocket buyers. Gains from trade arise because the seller is more impatient than the buyers. The seller, however, is privately informed about the quality of her asset, which could be high- or lowquality, and where higher cash flows are more likely to be obtained from a high-quality asset. Buyers compete by posting menus of bilateral contracts, where each contract is a security-price pair $(F, p)$, where $F$ maps cash flow $X$ to a payment $F(X)$ to be received by the buyer in the future. The seller can accept contracts from multiple menus, subject to a capacity constraint that the total cash flows that she sells do not exceed her endowment 1 As is standard in the literature on security design with asymmetric information, we restrict attention to securities for which the payoffs to the seller and the buyers are monotone in cash flows. We provide a full characterization of the perfect Bayesian Nash equilibria of this screening game.

Our setting features two frictions: the seller is privately informed about her asset quality and the securities market is non-exclusive. As a preliminary step, we consider two benchmarks in which we shut down each of these frictions in turn. First, we study the full information benchmark, where the asset quality is public information. Here, we show that the first-best allocations are implemented, as all asset cash flows are transferred from the seller to the buyers: equity is the optimal security design and it is priced at its full information expected value. Second, we study the exclusive markets benchmark, where the seller is restricted to trade with at most one buyer. Here, we show that an equilibrium exists if and only if the buyers' prior belief about the asset quality is below a threshold, in which case the equilibrium is unique and separating. In it, the seller of a high-quality asset (high-type) issues standard debt whereas the seller of a low-quality asset (low-type) issues equity, at prices that reflect the true underlying quality of the asset; that is, debt trades at high-type's valuation (high-valuation) whereas equity trades at low-valuation. The face value of the debt security is in turn chosen so that the low-type is indifferent between her equilibrium allocation and mimicking the high-type.

In the presence of asymmetric information, non-exclusive markets behave very differently from exclusive ones. In particular, we show that when markets are non-exclusive: (i) an equilibrium always exists and it is unique; (ii) separating contracts are never part of equilibrium; and (iii) equilibrium features semi-pooling for a wide range of parameters, in a sense that some but not all traded contracts are accepted by both seller types. In what follows, we discuss these findings and their implications in more detail.

In any equilibrium in non-exclusive markets, both seller types must issue the same nontrivial debt security (senior tranche). The high-type optimally chooses to retain (i.e. not sell)

\footnotetext{
${ }^{1}$ Such a capacity constraint prevents the seller from diluting the claims that she issues. For a detailed discussion of how our model relates to the literature on lack of commitment and dilution, see Section 2 .
} 
her remaining cash flows (junior tranche), while the low-type issues both the debt security and the remaining cash flows but to distinct buyers. Consistent with this, the senior tranche is mispriced, in the sense that its price reflects average rather than true asset quality; whereas the junior tranche is priced at its true, low-valuation. The face value of the debt security is in turn chosen so that it maximizes the payoff to the high-type seller, conditional on being priced at average-valuation.

Separating contracts are never part of equilibrium. One might intuitively think that, as cash flow retention is more costly for the low-type than for the high-type, it should be possible for buyers to separate the high-type seller by offering her a contract that requires enough cash flow retention to be unattractive for the low-type. When markets are non-exclusive, however, retention of cash flows cannot be enforced: there is always a profitable deviation for a buyer to offer to buy the retention implied by the contract of the high-type seller at a price slightly below low-valuation. Lack of exclusivity allows the low-type to then accept the contract meant for the high-type while also selling the resulting retention to the deviating-buyer; both the low-type and this buyer profit from such a deviation. By similar reasoning, we establish that in any equilibrium the low-type seller accepts any contract that is accepted by the high-type seller ${ }^{2}$ Standard debt then emerges as the optimal security design for the high-type seller, as it minimizes the mispricing she faces due to adverse selection. In addition, the low-type seller also issues her remaining cash flows at low-valuation to fully exploit gains from trade.

An equilibrium of our screening game with non-exclusive markets always exists and is unique, but it requires that some buyers post latent contracts. These are contracts that are offered in some buyers' menus but that are not accepted by the seller in equilibrium. To see why such contracts are needed, suppose to the contrary that buyers post menus that only contain the contracts that are accepted in equilibrium. Then, due to single-crossing, one can always find a profitable deviation for a buyer to "cream-skim" the high-type seller by offering to buy less cash flows than the equilibrium debt security at a price slightly below high-valuation. This is essentially the same reasoning for why pooling equilibria cannot exist in exclusive markets, as was first pointed out in the context of insurance markets by Rothschild and Stiglitz (1978). In non-exclusive markets, however, buyers can deter such deviations by posting auxiliary, latent contracts that ensure that, if a buyer were to deviate to cream-skim the high-type, then the low-type would also find it optimal to accept the deviant contract together with a collection of latent contracts from other buyers, rendering the cream-skimming deviation unprofitable ${ }^{3}$

Our theory's predictions are consistent with evidence from markets where exclusivity is diffi-

\footnotetext{
${ }^{2}$ This result extends the finding in Attar, Mariotti, and Salanié (2011) that separation is not possible in non-exclusive markets for divisible goods to a setting in which securities are designed optimally.

${ }^{3}$ The role of latent contracts in supporting equilibria in non-exclusive markets was first analyzed in Arnott and Stiglitz (1991) and Attar et al. (2011) in environments with moral hazard and adverse selection, respectively.
} 
cult to enforce. First, we provide a new rationale for the practice of tranching underlying cash flows that are sold separately in markets. Indeed, within the context of markets for commertial mortgage-backed securities (CMBS), where tranching is common practice, Ashcraft, Gooriah, and Kermani (2019) argue that complex products like collateralized debt obligations (CDOs) enabled informed parties in the securitization pipeline to reduce their cash flow retention in a way not observable to other market participants, suggesting that exclusivity is hard to enforce. Second, and in sharp contrast to conventional models, our theory predicts that the amount of cash flows retained by a seller should not predict differential pricing in the market for her senior tranches, but that it should predict differential quality of these tranches. This is consistent with findings in Ashcraft et al. (2019) that, in the CMBS market, initially retained cash flows sold into CDOs in the twelve months following a transaction are not correlated with the prices of the more senior tranches, though they do predict a higher probability of default of these tranches.

After the 2008-09 financial crisis, a number of reforms were discussed in the US, which would either directly or indirectly enhance exclusivity in contracting. For instance, the Dodd-Frank Act explicitly prohibits the sellers of asset-backed securities to engage in trades that have any material conflicts of interest with the investors of trades completed within the previous year $4^{4}$ A natural obstacle to the enforcement of such rules is the complexity of balance sheets of financial institutions and the opacity of markets in which they can trade. To address this, a number of complementary rules were implemented, primarily consisting of more stringent information disclosure requirements combined with the relocation of trading of certain securities from opaque over-the-counter markets to more transparent platforms. Our framework provides a natural laboratory within which one can evaluate the effects of such interventions.

First, we show that when the distribution of asset qualities in the market is exogenous (as in our baseline setting) non-exclusive markets increase welfare vis-à-vis exclusive markets if and only if they generate higher market liquidity (i.e. more trade), which is only the case when average asset quality is above a threshold. This finding contrasts with the by-now conventional 'ignorance is bliss' view of Dang, Gorton, and Holmström (2010) and Dang, Gorton, Holmström, and Ordonez (2017), according to which market liquidity and efficiency are maximized through complexity of assets and opacity of issuers' balance sheets. Our model instead provides a more nuanced view: to the extent that complexity/opacity inhibits exclusive contracting, its effects on liquidity and efficiency will depend on the average quality of assets in the market.

\footnotetext{
${ }^{4}$ Statement at Open Meeting: Asset-Backed Securities Disclosure and Registration, by Commissioner Kara M. Stein on Aug. 27, 2014 states that "Section 621 prohibits an underwriter, placement agent, initial purchaser, sponsor, or any affiliate or subsidiary of any such entity, of an asset-backed security from engaging in any transaction that would involve or result in any material conflict of interest with respect to any investor in a transaction arising out of such activity for a period of one year after the date of the first closing of the sale of the asset-backed security."
} 
Second, in some applications (e.g. loan origination), both the liquidity of markets and the manner by which claims are priced may impact efficiency by distorting incentives to improve asset quality. To address this, we consider a simple extension where we allow the seller (who is now also the asset originator) to exert costly, unobservable effort to increase the likelihood of having a high-quality asset. Here, we uncover a robust result: the average quality of originated assets is always lower with non-exclusive markets than with exclusive markets. Taking the above results together, we conclude that non-exclusive markets increase welfare vis-à-vis exclusive markets if and only if the potential (though not guaranteed) gains from increased market liquidity more than compensate for the (guaranteed) fall in asset quality. Thus, in contrast to Dang et al. (2010) and Dang et al. (2017), our results suggest that complexity/opacity is desirable only when efficiency gains are mostly driven by reallocation of assets in markets and originators need not be too incentivized to produce high-quality assets.

Our paper naturally relates to the literature that studies non-exclusive competition in markets plagued with adverse selection (e.g. Pauly Mark (1974); Jaynes (1978); Bisin and Gottardi (1999, 2003); Ales and Maziero (2009, 2016); Attar et al. (2011); Kurlat (2016). We contribute to this literature by studying the implication of non-exclusivity for the optimal design and pricing of financial securities.5 Within this literature, the paper that is closest to ours is Attar et al. (2011), who study non-exclusive competition in the market for lemons. Indeed, their model is equivalent to ours if we impose an additional restriction that requires the seller to issue equity claims only, i.e. the seller can only accept securities of the form $F(X)=q \cdot X$ for some $q \in[0,1]$. There are two important differences from Attar et al. (2011). First, due to optimal security design, we do not obtain Akerlof-like outcomes: there is always a non-trivial debt security that the high-type trades at average valuation and there is never a market collapse. Second, in our setting, the equilibrium demand for securities must generally be non-linear, in the sense that buyers must stand ready to buy one collection of securities at average or pooling valuation while another collection at low valuation. This feature yields novel predictions regarding issuance and pricing of securities which are in line with empirical evidence.

Finally, on the normative front, we contribute to a growing literature that studies the costs and benefits of transparency in financial markets plagued with adverse selection (e.g. Chemla and Hennessy (2014); Dang et al. (2010); Dang et al. (2017); Asriyan, Fuchs, and Green (2017, 2019a); Daley, Green, and Vanasco (2017)). This literature primarily focuses on how transparency affects the agents' ability to obtain additional information about the seller's asset quality (e.g. by observing signals). In contrast, we focus on the implications of transparency

\footnotetext{
${ }^{5}$ In a recent paper, $\mathrm{Li}(2019)$ also studies optimal security design in what is effectively a non-exclusive market, but in contrast to us (and the above literature) she focuses on a competitive search (rather than a strategic) environment.
} 
through its effects on exclusivity; that is, through the ability of an agent to observe and contract upon the set of trades that his counterparty enters into with other agents in the market.

Our paper is organized as follows. In Section 2, we present the setup of our model, and we establish two useful benchmarks against which to compare our results. In Section 3 , we characterize the equilibrium of our model. We consider the model's normative implications, which we relate to policy discussions, in Section 4 ; and its positive predictions, which we relate to empirical facts, in Section 5 .

\section{The Model}

There are two dates, indexed by $t \in\{1,2\}$. There is an asset seller (e.g. firm) and a large number $N$ of "deep pocket” buyers (e.g. investors). The seller's preferences are:

$$
U^{S}=c_{1}^{S}+\delta \cdot c_{2}^{S}
$$

where $\delta \in(0,1)$ and $c_{t}^{S}$ is the cash flow she receives in period $t$. A buyer's preferences are:

$$
U^{B}=c_{1}^{B}+c_{2}^{B}
$$

where $c_{t}^{B}$ is the cash flow he receives in period $t$. Thus, gains from trade between the seller and the buyers arise due to heterogeneity in discount factors. ${ }^{6}$

The seller is endowed with an asset that delivers a random cash flow $X$ in period $t=2$. The asset can be of high- or low-quality, denoted by $\theta \in\{H, L\}$, and its cash flow is distributed according to cdf $G_{\theta}$. We assume that $G_{\theta}$ has an associated pdf $g_{\theta}$ with full support on the interval $[0, \bar{X}]$ for some $\bar{X}>0$. The pdfs are in turn related by the monotone likelihood ratio property (MLRP); that is, $\frac{g_{H}(x)}{g_{L}(x)}$ is increasing in $x$. In the spirit of Akerlof $(1970)$, asymmetric information arises because the seller knows the quality $\theta$ of her asset, whereas the buyers are uninformed and have a prior belief $\mu_{0}=\mathbb{P}(\theta=H) \in(0,1)$.

To realize gains from trade, the seller can raise funds at $t=1$ by issuing securities backed by her asset cash flows to buyers. Formally, a security is a function $F:[0, \bar{X}] \rightarrow \mathbb{R}$ and its payoff is denoted by $F(x)$ when the realized cash flow is $X=x$. Let $\mathcal{F}$ denote the collection of securities issued by the seller, then we say that this collection is feasible if:

\footnotetext{
${ }^{6}$ The assumption that the seller is more impatient than the buyers is a common modeling device to rationalize gains from trade (e.g. DeMarzo and Duffie (1999); Biais and Mariotti (2005); DeMarzo (2005); Daley et al. (2016, 2017)). In practice, there are many reasons why an asset owner might want to raise funds by selling asset cash flows. For example, an entrepreneur who is financially constrained and has new profitable investment opportunities may benefit from selling a fraction of her assets to finance these new opportunities. Alternatively, asset securitization may allow loan originators to share-risks with market investors.
} 
1. (Capacity Constraint) Buyer's payoff, $F(x)$, and seller's payoff, $x-\sum_{F \in \mathcal{F}} F(x)$, are nonnegative for all $x$.

2. (Weak Monotonicity) Buyer's payoff, $F(x)$, and seller's payoff, $x-\sum_{F \in \mathcal{F}} F(x)$, are weakly increasing in $x$.

We denote the set of all feasible (collections of) securities by $\Delta$. Conditions (1) and (2) are generalizations of the limited liability and the monotonicity constraints in the literature on security design with asymmetric information (e.g. Nachman and Noe (1994); DeMarzo and Duffie (1999); Biais and Mariotti (2005)) to a setting with multiple securities. We interpret these conditions as technological or easy to enforce. Importantly, condition (1) states that neither the seller nor the buyers can trade cash flows that they do not have, which ensures that all promises are always met. It is a generalization of the capacity constraint in Attar et al. (2011) to security design, and it helps us isolate our mechanism from the one extensively studied in the literature; namely, the seller's ability to dilute the value of claims to asset cash flows by repeatedly issuing new claims on the same set of cash flows (e.g. Parlour and Rajan (2001); Santos and Scheinkman (2001a b); DeMarzo and He (2016); Admati, DeMarzo, Hellwig, and Pfleiderer (2018); Donaldson, Gromb, and Piacentino (2019)).7

The securities market is non-exclusive in the sense that trade between the seller and the buyers is bilateral, and a buyer cannot exclude the seller from trading with other buyers. Formally, we study the following screening game. Buyers move first and simultaneously post menus of contracts: a menu $\mathcal{M}^{i}$ posted by buyer $i$ is a set of contracts or security-price pairs $\left(F^{i}, p^{i}\right)$, and it contains at least the trivial pair $(0,0)$. Seller moves second and accepts one contract from each menu, subject to the associated collection of securities $\left(F^{1}, \ldots, F^{N}\right)$ being feasible 8 Finally, all contracts are executed: buyer $i$ makes transfer $p^{i}$ and seller receives transfer $\sum_{i} p^{i}$ at $t=1$; buyer $i$ receives payoff $F^{i}(x)$ and seller receives payoff $x-\sum_{i} F^{i}(x)$ at $t=2$ when the realized cash flow is $X=x$.

Given the menus posted by buyers, the seller chooses a collection of securities $\left(F^{1}, \ldots, F^{N}\right)$ to solve the following problem:

$$
\max _{\left(F^{i}, p^{i}\right) \in \mathcal{M}^{i}} \sum_{\forall i ;\left(F^{1}, \ldots, F^{N}\right) \in \Delta} p^{i}+\delta \cdot \mathbb{E}_{\theta}\left[X-\sum_{i} F^{i}(X)\right],
$$

where $\mathbb{E}_{\theta}[\cdot]$ is the expectations operator conditional on the seller's type being $\theta$. If indifferent between contracts of multiple buyers, we assume that the seller picks one randomly.

\footnotetext{
${ }^{7}$ In practice, in many markets, the presence of registries helps prevent agents from trading cash flows or assets that they do not have (e.g. asset-backed securities), and seniority rules help reduce agents' incentives to dilute the value of outstanding claims (e.g. corporate debt).

${ }^{8}$ The restriction that seller accept one contract from each menu is inessential, but it simplifies notation.
} 
When choosing what menu to post, buyer $i$ has a belief about the seller type who is likely to accept each contract from this menu. Let $\mu\left(F^{i}\right)$ denote the buyer $i$ 's belief that the seller is an $H$-type if she were to accept contract $\left(F^{i}, p^{i}\right)$ from her menu. Then, buyer $i$ chooses the menu $\mathcal{M}^{i}$ to solve the following problem:

$$
\max _{\mathcal{M}^{i}} \sum_{\left(F^{i}, p^{i}\right) \in \mathcal{M}^{i}} \mathbb{P}\left(\text { seller accepts } F^{i}\right) \cdot\left(-p^{i}+\mathbb{E}_{\mu}\left[F^{i}(X)\right]\right)
$$

where $\mathbb{E}_{\mu}\left[F^{i}(X)\right] \equiv \mu\left(F^{i}\right) \cdot \mathbb{E}_{H}\left[F^{i}(X)\right]+\left(1-\mu\left(F^{i}\right)\right) \cdot \mathbb{E}_{L}\left[F^{i}(X)\right]$ for any contract $\left(F^{i}, p^{i}\right)$ that is accepted with positive probability.

We characterize perfect Bayesian Nash equilibria of the above screening game, which has the following implications. First, the seller's acceptance strategy must be optimal, given the menus posted by the buyers (Seller Optimality). Second, each buyer's menu must be optimal given the menus posted by other buyers and the seller's acceptance strategy (Buyer Optimality). Finally, each buyer's belief about the seller type who is likely to accept a contract from his menu must be consistent with the seller's acceptance strategy and Bayes' rule (Belief Consistency).

Our environment features two frictions: (i) the seller is privately informed about $\theta$, and (ii) the securities market is non-exclusive. Before we proceed to the equilibrium analysis, it is useful to consider two benchmarks in which we shut down each of these frictions in turn.

\subsection{Benchmark without Asymmetric Information}

We first consider the allocations that would be attained in a setting without asymmetric information; that is, we assume that the seller's asset quality, $\theta$, is observable to the buyers.$^{9}$

Proposition 1 Suppose that buyers observe asset quality $\theta$ before posting their menus. Then, the aggregate cash flows issued by the $\theta$-type seller are $F_{\theta}(X)=X$, which are priced at their full information valuation $p_{\theta}=\mathbb{E}_{\theta}[X]$.

In the absence of asymmetric information, first-best allocations are obtained, as all gains from trade between the seller and the buyers are realized. Moreover, due to competition, the seller's cash flows are priced at their expected value, conditional on the true quality of the seller's asset. As we can see, in this setting, the fact that the securities market is non-exclusive has no bite. Therefore, all our novel findings will be due to the interaction of non-exclusivity with asymmetric information.

\footnotetext{
${ }^{9}$ Formally, we modify our equilibrium definition by in addition requiring that the buyers' belief $\mu(F)$ be equal to 1 if the type of the seller who issues security $F$ is $\theta=H$, and it is equal to 0 otherwise.
} 


\subsection{Benchmark with Exclusive Markets}

We next consider the allocations that would be attained in a setting where the securities market is exclusive; that is, the seller is effectively able to commit to trade with only one buyer.

Proposition 2 Suppose that the seller can accept a contract from only one menu. Then, an equilibrium exists if and only if $\mu_{0} \leq \widetilde{\mu} \in(0,1)$, in which case there exists $d^{E} \in(0, \bar{X})$ such that: 10

1. The aggregate cash flows issued by the high-type seller are $F_{H}(X)=\min \left\{d^{E}, X\right\}$, which are priced at high valuation $p_{H}=\mathbb{E}_{H}\left[\min \left\{d^{E}, X\right\}\right]$;

2. The aggregate cash flows issued by the low-type seller are given by $F_{L}(X)=X$, which are priced at low valuation $p_{L}=\mathbb{E}_{L}[X]$.

The first result in Proposition 2 is that, when an equilibrium exists, it is the so-called 'leastcostly separating' one. In this equilibrium, buyers screen the seller's types by offering two distinct contracts: $\left(F_{H}, p_{H}\right)$, which offers to buy less cash flows, but at high valuation; and $\left(F_{L}, p_{L}\right)$, which offers to buy all cash flows, but at low valuation. Moreover, because the securities market is exclusive, accepting contract $\left(F_{H}, p_{H}\right)$ necessarily implies retaining (i.e. not issuing/selling) the remaining cash flows. Because cash flow retention is more costly for the $L$-type seller, the security $F_{H}$ is designed so that the $L$-type is indifferent between issuing all of her cash flows at low valuation or mimicking the $H$-type by accepting contract $\left(F_{H}, p_{H}\right)$.

The second result is that standard debt is the optimal security by which to screen the hightype seller. This is because it is the security for which the value of retention differs the most among seller types, making retention of cash flows more costly for the $L$-type relative to other securities. In other words, debt relaxes the incentive compatibility constraint of the $L$-type the most relative to other securities. Such an equilibrium is often referred to as the least-costly because it is the one where buyers screen seller types by imposing the minimum cash flow retention necessary. Figure 1 provides a graphical illustration of these findings.

These results are closely related to the findings in the literature on security design with asymmetric information (DeMarzo, 2005; Daley et al., 2016). These papers study equilibria of a signaling game where, first, an informed seller chooses what security to issue and, then, uninformed competitive buyers bid for the issued security. In such a setting, the least-costly separating equilibrium always exists and it is the unique equilibrium that survives standard refinements. In our screening game, if the least-costly equilibrium exists, it is also unique 11

\footnotetext{
${ }^{10}$ For explicit expressions defining $d^{E}$ and $\widetilde{\mu}$, see the proof of the proposition in the Appendix.

${ }^{11}$ As there are many buyers, a given buyer's equilibrium menu is not pinned down. But, the allocation of cash flows between the seller and the buyers, as well as the pricing of these cash flows is unique.
} 

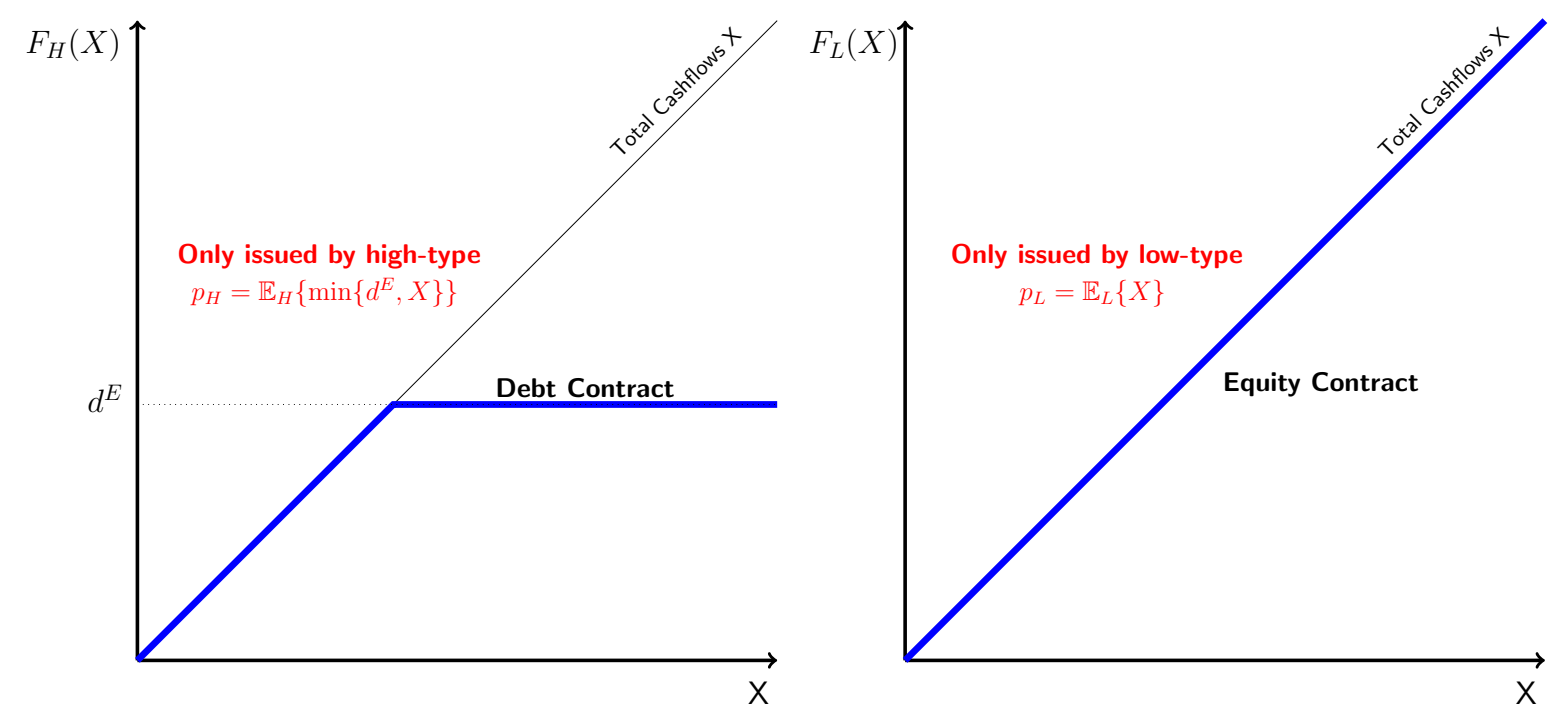

Figure 1: Security Design in Exclusive Markets. The left-panel depicts the security issued by the $H$-type seller, which is priced at high valuation; whereas the right-panel depicts the security issued by the $L$-type seller, which is priced at low valuation.

But, it may fail to exist for similar reasons to those first discussed in the context of insurance markets by Rothschild and Stiglitz (1978). In particular, when there is a pooling contract that is more attractive to the $H$-type than the contract $\left(F_{H}, p_{H}\right)$, there is a profitable deviation for a buyer to offer it and attract the seller. In the proof of Proposition 2, we show that such a deviation exists whenever the retention required for separation is relatively large and the lemons discount due to pooling of types is relatively low, as captured by the condition $\mu_{0}>\widetilde{\mu}$.

We show next that non-exclusive markets behave very differently from exclusive ones. In particular, we will show that when markets are non-exclusive: (i) equilibrium always exists and is unique, (ii) separating contracts are never part of equilibrium; and (iii) equilibrium features semi-pooling for a wide range of parameters, in a sense that some but not all traded contracts are accepted by both seller types. We will then argue that these findings have both important positive and normative implications.

\section{Equilibrium}

We are now ready to characterize the equilibrium of our model. As a first preliminary result, we show that all traded contracts must be priced fairly.

Lemma 1 Suppose that in equilibrium contract $(F, p)$ is accepted by the seller with positive probability. Then, $p=\mathbb{E}_{\mu}[F(X)]$. 
It is immediate that competition among buyers implies that each buyer must make zero profits in expectation. To prove Lemma 1, therefore, it suffices to show that buyers do not offer menus that involve cross-subsidization, i.e. contain some contracts that earn positive expected profits and others that earn negative expected profits. To this end, we show that if buyer $i$ were to post a contract $(F, p)$ that earned him positive expected profits, then there would be a profitable deviation for buyer $j \neq i$ : if buyer $j$ were not offering $(F, p)$ to begin with, then the deviation consists of simply adding this contract to his menu; instead, if buyer $j$ were also offering it, then the deviation is more subtle: it involves either buyer $j$ withdrawing his loss-making contracts or adding other, more attractive, contracts to his menu.

We next present our first important result, which states that in non-exclusive markets, screening seller types through cash flow retention is not possible.

Proposition 3 Suppose that in equilibrium a non-trivial contract $(F, p)$ is accepted by the hightype seller. Then, it must also be accepted by the low-type seller.

Proposition 3 highlights the importance of exclusivity for separation. Intuitively, suppose that the contracts $\left(F_{H}, p_{H}\right)$ and $\left(F_{L}, p_{L}\right)$ described in Proposition 2 were offered by buyer $i$ and accepted by the $H$ - and the $L$-type respectively. Consider then a deviation by buyer $j \neq i$, which allows the $L$-type to mimic the $H$-type seller: the buyer withdraws contract $\left(F_{H}, p_{H}\right)$ if he was also offering it, and instead offers contract $(\widetilde{F}, \widetilde{p})$ with $\widetilde{F}(X)=X-F_{H}(X)$ and $\widetilde{p}$ slightly below $\mathbb{E}_{L}\left[X-F_{H}(X)\right]$. This contract attracts the $L$-type, who now accepts contract $\left(F_{H}, p_{H}\right)$ from buyers other than $j$ and contract $(\widetilde{F}, \widetilde{p})$ from buyer $j$; moreover, buyer $j$ makes positive expected profits. Observe that such a deviation would not be profitable if markets were exclusive, since the $L$-type would not be allowed to accept both contract $(\widetilde{F}, \widetilde{p})$ from buyer $j$ and contract $\left(F_{H}, p_{H}\right)$ from other buyers. By analogous reasoning, we show that the $L$-type in fact must accept any non-trivial contract that is also accepted by the $H$-type.

In view of Lemma 1 and Proposition 3, we can without loss of generality focus on equilibria in which at most two contracts are traded: contract $\left(F_{S}, p_{S}\right)$ that is accepted by both types, and contract $\left(F_{J}, p_{J}\right)$ that is accepted by the $L$-type only (our motive for using these subscripts will be apparent shortly). Our next result characterizes the contract accepted by both types.

Proposition 4 In equilibrium, the aggregate cash flows issued by the high-type seller are $F_{S}(X)=$ $\min \left\{d^{N E}, X\right\}$, where:

$$
d^{N E}=\arg \max _{d \in[0, \bar{X}]} \mathbb{E}_{\mu_{0}}[\min \{d, X\}]-\delta \cdot \mathbb{E}_{H}[\min \{d, X\}]
$$

Moreover, $0<d^{N E} \leq \bar{X}$ where the last inequality is strict iff $\mu_{0} \leq \frac{\lim _{x \rightarrow \bar{X}} \delta \cdot \frac{g_{H}(x)}{g_{L}(x)}-1}{\lim _{x \rightarrow \bar{X}} \frac{g_{H}(x)}{g_{L}(x)}-1}$. 
In equilibrium, both seller types issue the same, non-trivial, debt security. Moreover, if buyers' belief about the underlying asset quality is sufficiently high, the seller issues a claim to all of her cash flows, i.e. $F_{S}(X)=X$. Standard debt is the optimal security design because it maximizes the payoff of the $H$-type seller subject to the $L$-type mimicking that issuance. This is because, among all feasible securities, standard debt is the security whose valuation is least sensitive to beliefs about underlying asset quality, i.e. it suffers the least from mispricing due to adverse selection and thus maximizes gains from trade with the $H$-type seller. The proof of Proposition 4 consists of showing that if contract $\left(F_{S}, p_{S}\right)$ with $p_{S}=\mathbb{E}_{\mu_{0}}\left[F_{S}(X)\right]$ was not offered in equilibrium, then there would be a profitable deviation for a buyer to offer security $F_{S}$ at price slightly below $p_{S}$ and attract the $H$-type seller.

Proposition 5 In equilibrium, the low-type seller issues all of her cash flows.

In addition to accepting the same contract as the $H$-type, the $L$-type seller issues his remaining cash flows $F_{J}(X)=X-F_{S}(X)$ at low valuation, in order to further exploit gains from trade. To see this, note that if the $L$-type were retaining some non-trivial cash flows $\widetilde{F}(X)$, then there would be a profitable deviation for a buyer to offer to purchase security $\widetilde{F}$ at price $\widetilde{p}$ slightly below $\mathbb{E}_{L}[X-\widetilde{F}(X)]$ and attract the $L$-type seller.

We have characterized the essential properties that any equilibrium must satisfy. First, asset cash flows are split into a senior $\left(F_{S}\right)$ and a junior $\left(F_{J}\right)$ tranche. While the $L$-type seller issues both tranches, each to a separate buyer, the $H$-type seller only issues the senior tranche but retains the junior one, as she is not willing to sell these cash flows at average valuation. Second, the $L$-type seller is effectively subsidized by the $H$-type seller in the market for the senior tranche, but she receives her full information valuation in the market for the junior tranche. Third, if an equilibrium exists, it must be unique in terms of the allocation of cash flows between the seller and the buyers. Figure 2 provides a graphical illustration of these findings.

The next proposition completes the equilibrium characterization by establishing existence.

\section{Proposition 6 An equilibrium exists.}

In equilibrium, it is essential that buyers post latent contracts, i.e. contracts that are part of buyers' menus but that are not accepted by the seller in equilibrium. To see this, suppose to the contrary that the buyers were only posting menus that contain the contracts $\left(F_{S}, p_{S}\right)$ and $\left(F_{J}, p_{J}\right)$. Consider a buyer who attempts to "cream-skim" the $H$-type seller by deviating to a contract $\left(F^{\prime}, p^{\prime}\right)$ with $F^{\prime}(X)=\min \left\{d^{\prime}, X\right\}$ for some $d^{\prime}<d^{N E}$ and $p^{\prime}<\mathbb{E}_{H}\left[F^{\prime}(X)\right]$. It is easy to show that there is a pair $\left(d^{\prime}, p^{\prime}\right)$ for which contract $\left(F^{\prime}, p^{\prime}\right)$ only attracts the $H$-type and, 

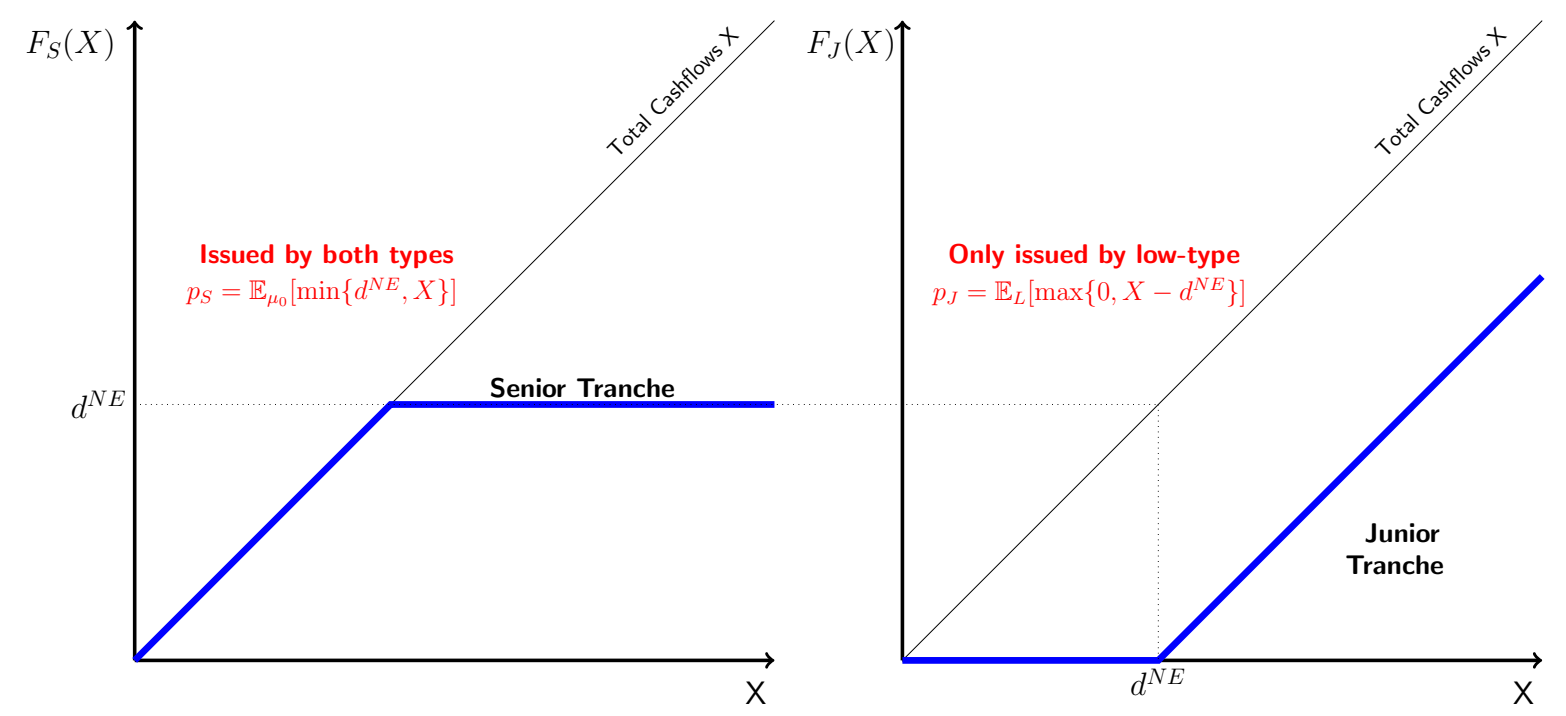

Figure 2: Security Design in Non-Exclusive Markets. The left-panel depicts the security issued by both seller types, which is priced at average valuation; whereas the right-panel depicts the security issued by the $L$-type seller only, which is priced at low valuation.

thus, must be profitable for the buyer. Note that this is essentially the same reasoning for why pooling equilibria cannot exist when the securities market is exclusive.

Thus, some buyers must include auxiliary contracts in their menus to deter such creamskimming deviations. These latent contracts ensure that it is always optimal for the $L$-type seller to accept any (deviating) contract that the $H$-type seller prefers to his equilibrium contract $\left(F_{S}, p_{S}\right)$. Let $\Omega$ denote the set of weakly profitable contracts $(\widetilde{F}, \widetilde{p})$, which the $H$-type weakly prefers to his equilibrium allocation, while the $L$-type weakly prefers his equilibrium allocation to any such contract. Suppose that the following contracts are posted by all buyers, in addition to the contracts $\left(F_{S}, p_{S}\right)$ and $\left(F_{J}, p_{J}\right)$. The first class of latent contracts is one that prices a continuum of securities at average valuation:

$$
\mathcal{L}_{\mu_{0}} \equiv\left\{(F, p): \exists(\widetilde{F}, \widetilde{p}) \in \Omega \text { s.t. } F(X)=\min \left\{d^{N E}-\widetilde{F}\left(d^{N E}\right), X-\widetilde{F}(X)\right\}, p=\mathbb{E}_{\mu_{0}}[F(X)]\right\}
$$

The second class of latent contracts is one that prices a continuum of securities at low valuation:

$\mathcal{L}_{L}=\left\{(F, p): \exists(\widetilde{F}, \widetilde{p}) \in \Omega\right.$ s.t. $\left.F(X)=X-\widetilde{F}(X)-\min \left\{d^{N E}-\widetilde{F}\left(d^{N E}\right), X-\widetilde{F}(X)\right\}, p=\mathbb{E}_{L}[F(X)]\right\}$.

We establish existence in two steps. First, we show that it is optimal for the seller to follow her equilibrium strategy rather than accept latent contracts. That the $H$-type does not accept latent contracts follows from the fact that these contracts are priced at average or low valuation, but the $H$-type already issues the most preferred security $F_{S}$ at average valuation (Proposition 
4). As for the $L$-type, by construction there is no feasible collection of latent contracts in $\mathcal{L}_{\text {avg }}$ that she could accept that would raise more funds than the equilibrium contract $\left(F_{S}, p_{S}\right)$; moreover, in equilibrium, the $L$-type could already issue all her remaining cash flows at low valuation, so the latent contracts in $\mathcal{L}_{\text {low }}$ are not attractive to her either.

Second, we show that any contract $(\widetilde{F}, \widetilde{p})$ with which a buyer deviates to cream-skim the $H$-type seller would also attract the $L$-type, and thus would not be profitable. The reason is that the $L$-type could in addition issue the contracts $\left(F^{\prime}, p^{\prime}\right) \in \mathcal{L}_{\text {avg }}$ with $F^{\prime}(X)=\min \left\{d^{N E}-\right.$ $\left.\widetilde{F}\left(d^{N E}\right), X-\widetilde{F}(X)\right\}$ and $\left(F^{\prime \prime}, p^{\prime \prime}\right) \in \mathcal{L}_{\text {low }}$ with $F^{\prime \prime}(X)=X-\widetilde{F}(X)-F^{\prime}(X)$. It is then easy to show that if the $H$-type seller prefers to accept the contract $(\widetilde{F}, \widetilde{p})$ instead of $\left(F_{S}, p_{S}\right)$, then the $L$-type seller must prefer to accept the contracts $(\widetilde{F}, \widetilde{p}),\left(F^{\prime}, p^{\prime}\right)$ and $\left(F^{\prime \prime}, p^{\prime \prime}\right)$ instead of $\left(F_{S}, p_{S}\right)$ and $\left(F_{J}, p_{J}\right)$. But then, the deviation to contract $(\widetilde{F}, \widetilde{p})$ could not be profitable.

It is instructive to contrast our findings with those of Attar et al. (2011); indeed, our setup coincides with theirs if we also restrict the seller to accept equity securities, i.e. $F(X)=q \cdot X$ for some $q \in[0,1]$. The first difference is that, due to optimal security design, we do not obtain the Akerlof (1970) outcome: as we have shown in Proposition 4 , there is always a non-trivial debt security that the $H$-type trades at average valuation and there is never a market collapse. ${ }^{12}$ In addition, from Propositions 4 and 5, we see that the equilibrium of our model features semi-pooling for a wide range of parameters, in a sense that some but not all traded contracts are accepted by both types. As we discuss in Section 5, this prediction is consistent with recent evidence from mortgage-backed securities markets. The second difference from Attar et al. (2011) is that in our setting the menus that buyers post must be "non-linear" whenever $d^{N E}<\bar{X}$. In particular, in order to deter cream-skimming, buyers (in aggregate) must stand willing to buy one collection of cash flows at average valuation and another collection at low valuation. Instead, if only equity trade were possible, it would suffice for buyers to price all cash flows at the same (average or low) valuation.

\section{Costs and Benefits of Non-Exclusivity}

As we already discussed in the introduction, after the global financial crisis, a number of transparency-enhancing financial market reforms were discussed in the US, which would either directly or indirectly enhance exclusivity in contracting. Despite of these efforts of policymakers and regulators, there is surprisingly little theoretical work on the policy implications of nonexclusivity in markets with asymmetric information. Motivated by this, in this section we consider the normative implications of our theory by studying the potential costs and benefits of non-exclusivity. First, we study the welfare properties of our baseline model, where the

\footnotetext{
${ }^{12}$ If only equity trade were possible, then only low-quality assets trade in equilibrium if $\mathbb{E}_{\mu_{0}}[X]<\delta \cdot \mathbb{E}_{H}[X]$.
} 
distribution of asset qualities is exogenous. Second, we consider a simple extension of the model that endogenizes average asset quality by allowing the seller to exert costly, unobservable effort to improve the quality of her asset.

\subsection{Non-Exclusivity and Market Liquidity}

We begin by introducing the notion of efficiency/welfare in our setting. Since buyers always break-even, efficiency is determined by the ex-ante expected payoff to the seller:

$$
W\left(\mu_{0}\right) \equiv \mu_{0} \cdot u_{H}\left(\mu_{0}\right)+\left(1-\mu_{0}\right) \cdot u_{L}\left(\mu_{0}\right)
$$

where $u_{\theta}\left(\mu_{0}\right)$ denotes the equilibrium payoff of a $\theta$-type seller when the buyers' prior belief that the seller is $H$-type is $\mu_{0} \sqrt{13}$ In what follows, we will sometimes use superscripts to indicate the outcomes in the first-best $(F B)$, exclusive $(E)$ or non-exclusive $(N E)$ market settings.

In the presence of asymmetric information, the equilibrium allocations may be distorted away from first-best for two reasons. First, due to retention of cash flows by the $H$-type seller, some gains from trade remain unrealized. We say that the market is more liquid when more gains from trade between the seller and the buyers are realized, i.e. when cash flow retention is lower. Second, because the prices of claims need not reflect true underlying asset quality $\theta$, the $H$-type seller may effectively subsidize the $L$-type seller. When this occurs, we say that there is mispricing. To illustrate the effects of these distortions, the payoff of a $\theta$-type seller can be expressed as follows:

$$
\begin{aligned}
& u_{L}\left(\mu_{0}\right)=\underbrace{\mathbb{E}_{L}[X]}_{=u_{L}^{F B}}+\underbrace{\Delta\left(\mu_{0}\right)}_{\text {Mispricing Subsidy }}, \\
& u_{H}\left(\mu_{0}\right)=\underbrace{\mathbb{E}_{H}[X]}_{=u_{H}^{F B}}-\underbrace{(1-\delta) \cdot \mathbb{E}_{H}\left[\max \left\{X-d\left(\mu_{0}\right), 0\right\}\right]}_{\text {Cost of Retention }}-\underbrace{\frac{1-\mu_{0}}{\mu_{0}} \cdot \Delta\left(\mu_{0}\right)}_{\text {Mispricing Tax }} .
\end{aligned}
$$

Since the mispricing of claims generates a transfer from the $H$-type to the $L$-type seller, equilibrium welfare is distorted away from first-best only due to inefficient cash flow retention:

$$
W\left(\mu_{0}\right)=\underbrace{\mu_{0} \cdot \mathbb{E}_{H}[X]+\left(1-\mu_{0}\right) \cdot \mathbb{E}_{L}[X]}_{=W^{F B}\left(\mu_{0}\right)}-\underbrace{\mu_{0} \cdot(1-\delta) \cdot \mathbb{E}_{H}\left[\max \left\{X-d\left(\mu_{0}\right), 0\right\}\right]}_{\text {Expected Cost of Retention }}
$$

It follows that, in our baseline setting, a more liquid market is also more efficient. Therefore, when an equilibrium with exclusive markets exists, non-exclusive markets are more efficient

\footnotetext{
${ }^{13}$ We are using the fact that the average quality of assets and the buyers' prior belief are the same.
} 


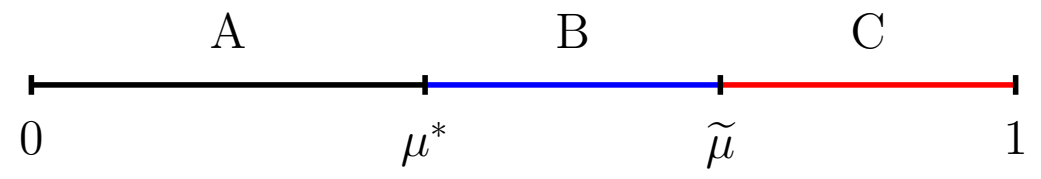

Figure 3: Which market structure is more efficient for an exogenously given average quality $\mu_{0}$ ? Region A depicts the values of $\mu_{0}$ for which exclusive markets dominate non-exclusive markets. Region B depicts the values for which non-exclusive markets dominate exclusive markets. Region $\mathrm{C}$ depicts the values for which an equilibrium with exclusive markets does not exist.

than exclusive markets if and only if $d^{N E}\left(\mu_{0}\right)>d^{E}{ }^{14}$ The next proposition characterizes when this is the case.

Proposition 7 There exists $\mu^{*} \in(0, \widetilde{\mu})$, where $\widetilde{\mu}$ is as in Proposition 2, such that the welfare with non-exclusive markets is greater than with exclusive markets if and only if $\mu_{0} \in\left(\mu^{*}, \widetilde{\mu}\right]$.

Figure 3 illustrates this result graphically. The proof is intuitive. First, $d^{E} \in(0, \bar{X})$ is independent of $\mu_{0}$, since cash flow retention with exclusive markets is pinned down by incentive compatibility of the $L$-type seller and does not depend on the composition of the pool of sellers. Second, $d^{N E}\left(\mu_{0}\right)$ is continuous and monotonically increasing in $\mu_{0}$, since cash flow retention with exclusive markets is determined by the $H$-type's maximization problem in (5); and retention declines when the lemons discount is smaller. Moreover, it is straightforward to show that $d^{N E}\left(\mu_{0}\right)$ is smaller than $d^{E}$ when $\mu_{0}$ is sufficiently small but goes to $\bar{X}$ as $\mu_{0}$ goes to 1 . The threshold $\mu^{*}$ is then defined to be the value of $\mu_{0}$ at which $d^{N E}\left(\mu_{0}\right)=d^{E}$.

These findings contrast with the by-now conventional 'ignorance is bliss' view of Dang et al. (2010) and Dang et al. (2017), according to which market liquidity and efficiency are maximized through complexity of assets and opacity of issuers' balance sheets. Our results instead suggest that to the extent that complexity/opacity inhibits exclusive contracting, it actually reduces market liquidity and efficiency whenever the underlying asset quality is low.

\subsection{Non-Exclusivity and Origination Incentives}

In the previous section, we showed that non-exclusive markets may either increase or decrease market liquidity, and therefore efficiency, depending on the average quality of assets. Recall, however, that non-exclusive markets always induce mispricing of claims, whereas exclusive markets do not 15 In our baseline setting, such mispricing was irrelevant for efficiency, as the

\footnotetext{
${ }^{14} \mathrm{We}$ omit the dependence of $d^{E}, u_{H}^{E}$ and $u_{L}^{E}$ on $\mu_{0}$, since the exclusive markets allocations are independent of the buyers' prior belief.

${ }^{15}$ In particular, $\Delta^{E}=\Delta^{F B}=0$ and $\Delta^{N E}\left(\mu_{0}\right)=\mathbb{E}_{\mu_{0}}\left[\min \left\{d^{N E}\left(\mu_{0}\right), X\right\}\right]-\mathbb{E}_{L}\left[\min \left\{d^{N E}\left(\mu_{0}\right), X\right\}\right]$.
} 
distribution of asset quality was exogenous. In many applications, however, such mispricing may impact efficiency by distorting incentives to improve asset quality, e.g. loan origination. To address this, we now explore how non-exclusivity, through its effects on market liquidity and the pricing of claims, affects incentives to originate high quality assets.

We consider a simple extension of our baseline setting, where we now allow the seller (who is now also an asset originator) to exert costly, unobservable effort $c(q)$ to ensure that her asset is of high quality with probability $q \in[0,1]$. For interior solution, we suppose that $c(0)=c^{\prime}(0)=0$, $c^{\prime}(q)>0$ and $c^{\prime \prime}(q)>0$ for $q \in(0,1)$, and $\lim _{x \rightarrow 1} c^{\prime}(x)=\infty \sqrt{16}$ Given the buyers' prior belief $\mu_{0}$, efficiency is given by the ex-ante payoff of the seller, now given by:

$$
W\left(\mu_{0}\right)=\max _{q} q \cdot u_{H}\left(\mu_{0}\right)+(1-q) \cdot u_{L}\left(\mu_{0}\right)-c(q)
$$

where $u_{\theta}\left(\mu_{0}\right)$ denotes the payoff of a $\theta$-type seller in the equilibrium of the trading stage as defined in Section 2, for given belief $\mu_{0}$. The solution $q^{*}$ to problem $(12)$ exists, is unique, and satisfies:

$$
c^{\prime}\left(q^{*}\right)=\underbrace{\mathbb{E}_{H}[X]-\mathbb{E}_{L}[X]-(1-\delta) \cdot \mathbb{E}_{H}\left[\max \left\{X-d\left(\mu_{0}\right), 0\right\}\right]-\frac{\Delta\left(\mu_{0}\right)}{\mu_{0}}}_{=u_{H}\left(\mu_{0}\right)-u_{L}\left(\mu_{0}\right)} .
$$

An equilibrium of the entire game now in addition requires that (i) given the seller's payoffs $\left\{u_{\theta}\left(\mu_{0}\right)\right\}_{\theta}$ at the trading stage, her effort choice is optimal, i.e. solves (13); and (ii) the buyers' prior belief is consistent with the seller's optimal effort choice, i.e. $\mu_{0}=q^{*}$. It is straightforward to show that, when markets are non-exclusive, an equilibrium exists, although it may not exist when markets are exclusive for the same reason as in our baseline model 17 Further, in either market structure (exclusive or non-exclusive), when an equilibrium exists, it is unique in terms of the origination effort and the allocation of cash flows and their pricing at the trading stage.

From equation (13), we see that both market liquidity (as captured by $d\left(\mu_{0}\right)$ ) and the extent to which the claims are mispriced (as captured by $\Delta\left(\mu_{0}\right)$ ) are relevant for determining the originator's effort incentives. Moreover, even though market liquidity may be higher or lower in non-exclusive markets (see Proposition 7), mispricing of claims is only a feature of non-exclusive markets. As we show next, this latter fact is crucial for understanding origination incentives.

Proposition 8 When asset quality is endogenous, and an equilibrium exists in both market

\footnotetext{
${ }^{16}$ This formulation is standard and has been employed in several papers that study the effect of secondary market liquidity on origination incentives (e.g. Chemla and Hennessy (2014); Vanasco (2017); Caramp (2017); Neuhann (2017); Daley, Green, and Vanasco (2017); Fukui (2018); Asriyan, Fuchs, and Green (2019b)).

${ }^{17}$ If effort cost is too low, then the seller's optimal effort $q^{*}$ is always above $\tilde{\mu}$. But then, for $\mu_{0}=q^{*}>\widetilde{\mu}$, an equilibrium at the trading stage does not exist.
} 


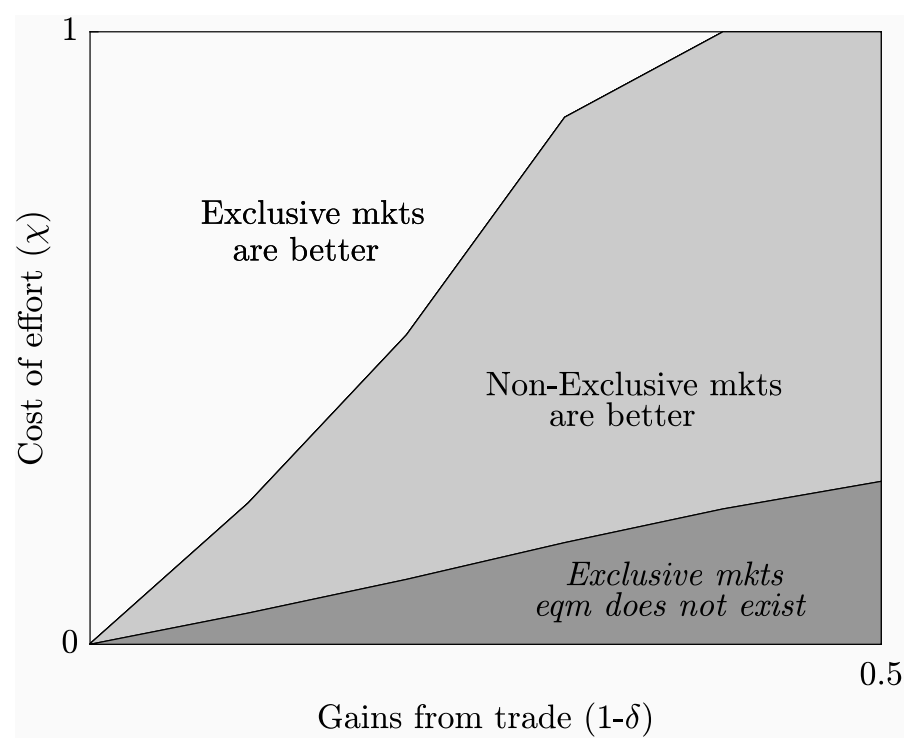

Figure 4: Which market structure is more efficient when average quality is endogenous? The unshaded region depicts parameter values for which exclusive markets dominate non-exclusive ones. The lightshaded region depicts parameter values for which non-exclusive markets dominate exclusive ones. The darkshaded region depicts parameter values for which an equilibrium with exclusive markets does not exist.

structures, then the average quality of originated assets is lower with non-exclusive markets than with exclusive markets, i.e. $0<\mu_{0}^{N E}<\mu_{0}^{E}<\mu_{0}^{F B}<1$.

Proposition 8 establishes a very strong result: non-exclusive markets always implement lower equilibrium asset quality than exclusive markets. The reason behind it is intuitive, and it is driven by fundamental differences between exclusive and non-exclusive markets. Recall that the originator's incentive to exert effort increases with the payoff gap between seller types, $u_{H}\left(\mu_{0}\right)-u_{L}\left(\mu_{0}\right)$ (see equation (13)). The proof then consists of showing that this gap is always smaller in non-exclusive markets. First, for interior $\mu_{0}$ (as is the case in equilibrium), the $L$-type seller is strictly better off in non-exclusive markets, $u_{L}^{N E}\left(\mu_{0}\right)=\mathbb{E}_{L}[X]+\Delta^{N E}\left(\mu_{0}\right)>\mathbb{E}_{L}[X]=u_{L}^{E}$, due to the mispricing in the market for the senior tranche. Second, for any $\mu_{0} \leq \tilde{\mu}$ (i.e., when an equilibrium in exclusive markets exists), the $H$-type seller is worse off in non-exclusive markets, $u_{H}^{N E}\left(\mu_{0}\right) \leq u_{H}^{E}$, and strictly so if $\mu_{0}<\widetilde{\mu}$; otherwise, we show that in exclusive markets there would be a profitable deviation for a buyer to offer a contract that attracts both seller types. ${ }^{18}$ In a nutshell, non-exclusive markets benefit sellers of lower quality assets at the expense of sellers of higher quality assets, reducing incentives to originate high-quality assets.

By combining the results Propositions 7 and 8, we conclude that non-exclusive markets can only be more efficient if the potential (though not guaranteed) gains from increased market

\footnotetext{
${ }^{18} \mathrm{In}$ fact, $\widetilde{\mu}$ is exactly equal to the buyers' prior belief $\mu_{0}$ at which $u_{H}^{N E}\left(\mu_{0}\right)=u_{H}^{E}$, where $u_{H}^{E}$ is independent of $\mu_{0}$ whereas $u_{H}^{N E}\left(\mu_{0}\right)$ is increasing in $\mu_{0}$.
} 
liquidity more than compensate for the (guaranteed) fall in asset quality. Figure 4 illustrates that this happens when the gains from market trade (as captured by $1-\delta$ ) are large relative to the cost of exerting effort (as captured by $\chi$ ), where we use a simple parameterization, $c(q)=\chi \cdot \frac{q^{2}}{1-q}$.

These findings provide a further contrast to Dang et al. (2010) and Dang et al. (2017), by showing that complexity/opacity is desirable only in environments where efficiency gains are mostly driven by reallocation of assets in markets and at the same time the originators need not be too incentivized to produce high-quality assets.

\section{$5 \quad$ Empirical Implications}

Our model has important implications for markets in which exclusivity is difficult to enforce. This is likely to be the case in markets where sellers' (e.g. firms, banks) risk exposures or trades are either not observable or hard to understand by other market participants (e.g. investors, regulators, courts). Understanding the implications of non-exclusivity is particularly relevant for the study of modern financial markets, where the increasing complexity of assets and balance sheets of financial intermediaries combined with the opacity of markets where these assets are traded makes it virtually impossible for outsiders to ensure that a seller retains a particular risk-exposure. In what follows, we present the novel empirical implications of our model and relate them to empirical evidence in the market for mortgage-backed securities.

Prediction 1. As exclusivity becomes harder to enforce, the practice of splitting asset cash flows into different tranches that are sold separately in markets is more likely to occur.

Indeed, in recent decades, the expansion of securitization and of the practice of tranching loan cash flows coincided with an increase in the complexity of financial intermediaries' balance sheets, whose risk-exposures became harder to understand and contract upon. As argued in a recent paper by Ashcraft et al. (2019), the complexity of collateralized debt obligations (CDOs) "enabled informed parties in the commercial mortgage-backed securitization pipeline to reduce their skin-in-the-game [retention] in a way not observable to other market participants."

Prediction 2. In non-exclusive markets, the amount of cash flows retained should not predict differential pricing of securities in the market for senior tranches.

This prediction follows from Propositions 3 and 4 , which state that the senior tranche, issued by all seller types in equilibrium, is priced at average valuation. As a result, whether the seller retains ( $H$-type) or sells ( $L$-type) her junior tranche does not affect its pricing. This result is consistent with findings in Ashcraft et al. (2019), who study cash flow retention and its relation 
to security performance in the conduit segment of the commercial mortgage-backed securities market 19 They find that the fraction of initially retained cash flows sold into CDOs in the twelve months following a transaction, i.e., not observed at the time of the transaction, is not correlated with the prices of the more senior tranche.

Prediction 3. In non-exclusive markets, the amount of cash flows retained should predict differential quality of the senior tranches.

This prediction follows from Propositions 4 and 5, which state that while the $H$-type seller only issues a senior tranche, and thus retains a junior tranche, the $L$-type seller issues both tranches to distinct buyers, and thus does not retain cash flows in equilibrium. This result is consistent with evidence in Ashcraft et al. (2019), who find that a higher fraction of initial cash flow retention sold into CDOs predicts a higher probability of default of the more senior tranches, even after controlling for all information available at issuance.

To the best of our knowledge, the predictions 2 and 3 are not consistent with other models of security design. We therefore interpret the evidence in Ashcraft et al. (2019) as supportive of our main model mechanism.

Prediction 4. As exclusivity becomes harder to enforce, the quality of originated assets declines.

This prediction is effectively a re-statement of Proposition 8. Though we are not aware of a formal test of this prediction, it is broadly consistent with the well-known stylized fact that the US credit boom of the early 2000s, fueled by securitization and financial engineering of complex assets traded in opaque markets, has been associated with falling lending standards and a decline in the quality of originated assets (e.g. Mian and Sufi (2009); Keys et al. (2010); Dell'Ariccia et al. (2012)). This is commonly attributed to the observed decline in the originators' cash flow retention (i.e. less skin-in-the-game) that the securitization process had apparently enabled (Parlour and Plantin (2008); Chemla and Hennessy (2014); Vanasco (2017)). As we showed in Section 4, however, the manner by which secondary markets price claims is also an essential determinant of the originators' incentives, above and beyond overall cash flow retention.

\footnotetext{
${ }^{19}$ They study the retention of B-piece investors, who are buyers that perform due-diligence and re-underwrite all of the loans in a given pool, indicating there is no asymmetric information between the actual seller and the B-piece investors. Importantly, even though the size of the B-piece is disclosed to other (uninformed) buyers, how much the B-piece buyer actually retains over time is not transparent to these buyers. See Ashcraft et al. (2019) for a more detailed description of the environment and empirical strategy.
} 


\section{Concluding Remarks}

We revisit the classic problem of a seller who is privately informed about her asset and needs to raise funds from uninformed buyers by issuing securities backed by her asset cash flows. We depart from the traditional literature by positing that the securities market is non-exclusive; that is, the seller cannot commit to trade with only one buyer. We show that non-exclusive markets behave very differently from exclusive ones in the presence of information asymmetries. In particular, when markets are non-exclusive: (i) an equilibrium always exists and it is unique; (ii) separating contracts are never part of equilibrium; and (iii) equilibrium features semi-pooling for a wide range of parameters. Our model's predictions are consistent with empirical evidence on the issuance and pricing of mortgage-backed securities, and we use the theory to evaluate some of the reforms, recently proposed and implemented, aimed at enhancing transparency and exclusivity in financial markets. 


\section{References}

Admati, A. R., P. M. Demarzo, M. F. Hellwig, And P. Pfleiderer (2018): "The leverage ratchet effect," The Journal of Finance, 73, 145-198.

Akerlof, G. (1970): "The Market for Lemons: Quality Uncertainty and the Market Mechanism," Quaterly Journal for Economics, 84.

Ales, L. And P. Maziero (2009): "Non-Exclusive Dynamic Contracts," Competition, and the Limits of Insurance, kworking paper.

- (2016): "Non-exclusive dynamic contracts, competition, and the limits of insurance," Journal of Economic Theory, 166, 362-395.

Arnott, R. And J. E. Stiglitz (1991): "Moral hazard and nonmarket institutions: Dysfunctional crowding out of peer monitoring?" The American Economic Review, 179-190.

Ashcraft, A. B., K. Gooriah, And A. Kermani (2019): "Does skin-in-the-game affect security performance?" Journal of Financial Economics.

Asriyan, V., W. Fuchs, And B. Green (2017): "Information spillovers in asset markets with correlated values," American Economic Review, 107, 2007-40.

(2019a): "Aggregation and design of information in asset markets with adverse selection," Available at SSRN 2959043.

(2019b): "Liquidity sentiments," American Economic Review, 109, 3813-48.

Attar, A., T. Mariotti, and F. Salanié (2011): "Nonexclusive competition in the market for lemons," Econometrica, 79, 1869-1918.

Biais, B. And T. Mariotti (2005): "Strategic liquidity supply and security design," Review of Economic Studies, 72, 615-649.

Bisin, A. And P. GotTARdi (1999): "Competitive equilibria with asymmetric information," Journal of Economic Theory, 87, 1-48.

(2003): "Competitive markets for non-exclusive contracts with adverse selection: The role of entry fees," Review of Economic Dynamics, 6, 313-338.

Caramp, N. (2017): "Sowing the seeds of financial crises: Endogenous asset creation and adverse selection," Available at SSRN $300997 \%$.

Chemla, G. And C. Hennessy (2014): "Skin in the game and moral hazard," Journal of Finance.

Daley, B., B. S. Green, And V. Vanasco (2016): "Security design with ratings," Available at SSRN 2940791.

- (2017): "Securitization, ratings, and credit supply," .

Dang, T. V., G. Gorton, And B. Holmström (2010): "Financial Crises and the Opti- 
mality of Debt for Liquidity," Working Paper.

Dang, T. V., G. Gorton, B. Holmström, And G. Ordonez (2017): "Banks as secret keepers," American Economic Review, 107, 1005-29.

Dell'Ariccia, G., D. Igan, And L. U. Laeven (2012): "Credit booms and lending standards: Evidence from the subprime mortgage market," Journal of Money, Credit and Banking, 44, 367-384.

Demarzo, P. And Z. He (2016): "Leverage dynamics without commitment," Tech. rep., National Bureau of Economic Research.

DeMarzo, P. M. (2005): "The pooling and tranching of securities: A model of informed intermediation," Review of Financial Studies, 18, 1-35.

Demarzo, P. M. And D. Duffie (1999): "A Liquidity-Based Model of Security Design," Econometrica, 67, 65-99.

Donaldson, J. R., D. Gromb, and G. Piacentino (2019): "The paradox of pledgeability," Journal of Financial Economics.

Fukui, M. (2018): “Asset quality cycles," Journal of Monetary Economics, 95, 97-108.

JAYNES, G. D. (1978): "Equilibria in monopolistically competitive insurance markets," Journal of Economic Theory, 19, 394-422.

Keys, B. J., T. Mukherjee, A. Seru, And V. Vikrant (2010): "Did securitization lead to lax screening? Evidence from Subprime Loans," Quarterly Journal of Economics.

Kurlat, P. (2016): "Asset markets with heterogeneous information," Econometrica, 84, 3385.

Leland, H. E. AND D. H. Pyle (1977): "Informational asymmetries, financial structure, and financial intermediation," Journal of Finance, 32, 371-387.

LI, Q. (2019): "Securitization and Liquidity Creation in Markets with Adverse Selection," Available at SSRN 2932441.

Mian, A. AND A. Sufi (2009): "The consequences of mortgage credit expansion: Evidence from the US mortgage default crisis," The Quarterly Journal of Economics, 124, 1449-1496.

Nachman, D. And T. NoE (1994): "Optimal Design of Securities under Asymmetric Information," Review of Financial Studies, 7, 1-44.

Neuhann, D. (2017): "Macroeconomic effects of secondary market trading," Available at SSRN 3095730.

Parlour, C. A. And G. Plantin (2008): "Loan sales and relationship banking," The Journal of Finance, 63, 1291-1314.

Parlour, C. A. AND U. RAJAN (2001): "Competition in loan contracts," American Economic Review, 91, 1311-1328. 
Pauly Mark, V. (1974): "Overinsurance and Public Provision of Insurance: the Roles of Moral Hazard and Adverse Selection," Quarterly Journal of Economics, 88, 44-62.

Rothschild, M. And J. Stiglitz (1978): "Equilibrium in competitive insurance markets: An essay on the economics of imperfect information," in Uncertainty in economics, Elsevier, $257-280$.

Santos, T. And J. A. Scheinkman (2001a): "Competition among exchanges," The Quarterly Journal of Economics, 116, 1027-1061.

- (2001b): "Financial intermediation without exclusivity," American Economic Review, 91, 436-439.

VAnAsco, V. (2017): "The downside of asset screening for market liquidity," The Journal of Finance, 72, 1937-1982. 


\section{A Appendix}

Proof of Proposition 1. The proof is straightforward.

Proof of Proposition 2, We first show that each buyer must make zero expected profits in equilibrium. It is clear that each buyer must make non-negative expected profits. Let $\Pi$ denote the aggregate profits of the buyers and suppose to the contrary that $\Pi>0$. Let $\left(F_{\theta}, p_{\theta}\right)$ denote the contract that is accepted by the $\theta$-type (which could be the same for both types). Consider buyer $i$ whose expected profits are less than $\frac{\Pi}{2}$, and suppose that he were to deviate and add contracts $\left\{\left(F_{\theta}, p_{\theta}+\varepsilon\right)\right\}_{\theta=H, L}$ to his menu. Clearly, the high- and the low-type will now accept the contracts $\left(F_{H}, p_{H}+\varepsilon\right)$ and $\left(F_{L}, p_{L}+\varepsilon\right)$ respectively, instead of $\left(F_{H}, p_{H}\right)$ and $\left(F_{L}, p_{L}\right)$, as their relative attractiveness to each type remains unchanged. Hence, such a deviation must be profitable for $\varepsilon$ small enough.

Next, there are two possible candidate equilibria: (i) a pooling equilibrium, i.e., both types accept the same contract $\left(F_{\mu_{0}}, p_{\mu_{0}}\right)$, and (ii) a separating equilibrium, i.e., $\theta$-type accepts contract $\left(F_{\theta}, p_{\theta}\right)$, with $\left(F_{H}, p_{H}\right) \neq\left(F_{L}, p_{L}\right)$. We first show that pooling equilibria cannot exist.

Consider a candidate pooling equilibrium. In such an equilibrium it must be that $p_{\mu_{0}}=$ $\mathbb{E}_{\mu_{0}}\left[F_{\mu_{0}}(X)\right]$, because each buyer must earn zero expected profits. Suppose that buyer $i$ were offering this contract. First, it must be that $F_{\mu_{0}}(X)=\min \left\{d^{*}, X\right\}$ with:

$$
d^{*}=\arg \max _{d \in[0, \bar{X}]} \mathbb{E}_{\mu_{0}}[\min \{d, X\}]+\delta \cdot \mathbb{E}_{H}[X-\min \{d, X\}]
$$

where $d^{*}>0$ (see proof of Proposition 4). If such a contract were not offered, buyer $j \neq i$ could deviate and add contract $\left(F^{\prime}, p^{\prime}\right)$ to his menu, with $F^{\prime}(X)=\min \left\{d^{*}, X\right\}$ and $p^{\prime}$ slightly below $\mathbb{E}_{\mu_{0}}\left[\min \left\{d^{*}, X\right\}\right]$; such a contract would clearly attract the high-type and, possibly, the low-type; and, it would be profitable (by monotonicity of $F^{\prime}(\cdot)$ and MLRP). Second, consider a deviation by buyer $j \neq i$ to add contract $\left(F^{\prime \prime}, p^{\prime \prime}\right)$ to his menu, with $F^{\prime \prime}(X)=\min \left\{d^{\prime \prime}, X\right\}$ with $p^{\prime \prime}=\mathbb{E}_{\mu_{0}}\left[\min \left\{d^{\prime \prime}, X\right\}\right]+\varepsilon$ such that:

$$
\mathbb{E}_{\mu_{0}}\left[\min \left\{d^{*}, X\right\}\right]+\delta \cdot \mathbb{E}_{L}\left[X-\min \left\{d^{*}, X\right\}\right]=p^{\prime \prime}+\delta \cdot \mathbb{E}_{L}\left[X-\min \left\{d^{\prime \prime}, X\right\}\right]
$$

and

$$
\mathbb{E}_{\mu_{0}}\left[\min \left\{d^{*}, X\right\}\right]+\delta \cdot \mathbb{E}_{H}\left[X-\min \left\{d^{*}, X\right\}\right]<p^{\prime \prime}+\delta \cdot \mathbb{E}_{H}\left[X-\min \left\{d^{\prime \prime}, X\right\}\right],
$$

i.e., contract $\left(F^{\prime \prime}, p^{\prime \prime}\right)$ attracts the high-type but not the low-type. By MLRP, we know that $\frac{\partial \mathbb{E}_{H}\left[X-\min \left\{d^{\prime \prime}, X\right\}\right]}{\partial d^{\prime \prime}}<\frac{\partial \mathbb{E}_{L}\left[X-\min \left\{d^{\prime \prime}, X\right\}\right]}{\partial d^{\prime \prime}}$ and therefore, for $\varepsilon$ small, there exists a $d^{\prime \prime}<d^{*}$ that satisfies these conditions. Hence, such a deviation is profitable.

Consider a candidate separating equilibrium. Suppose that buyer $i$ were offering contracts $\left(F_{H}, p_{H}\right)$ and $\left(F_{L}, p_{L}\right)$. If $p_{H}<\mathbb{E}_{H}\left[F_{H}(X)\right]$ and $p_{L}>\mathbb{E}_{L}\left[F_{L}(X)\right]$, or if $p_{H}>\mathbb{E}_{H}\left[F_{H}(X)\right]$ and $p_{L}<\mathbb{E}_{L}\left[F_{L}(X)\right]$, then consider a deviation by buyer $j \neq i$ to only offer the profit making contract in his menu (in addition to the trivial contract). Since such a contract would still be accepted with positive probability by the type it is intended for, such a deviation is profitable. Thus, it must be that $p_{\theta}=\mathbb{E}_{\theta}\left[F_{\theta}(X)\right]$.

Next, observe that it must be that $F_{L}(X)=X$. Suppose not and that contract $\left(F_{L}, p_{L}\right)$ is offered by buyer $i$. Consider a deviation by buyer $j \neq i$ to to add contract $\left(F^{\prime}, p^{\prime}\right)$ to his menu, with $F^{\prime}(X)=X$ and $p^{\prime}=\mathbb{E}_{L}[X]-\varepsilon$. Since $F_{L}(x) \neq x$ for some $x \in[0, \bar{X}]$ and $F_{L}(\cdot)$ 
is monotonic, it must be that $\mathbb{E}_{L}\left[F_{L}(X)\right]+\delta \cdot \mathbb{E}_{L}\left[X-F_{L}(X)\right]<\mathbb{E}_{L}[X]$. Hence, for $\varepsilon$ small enough, this contract would be accepted by the low-type and, possibly, the high-type; and it must be profitable for buyer $j$. Finally, observe that it must be that:

$$
F_{H}=\arg \max _{F \in \Delta} \mathbb{E}_{H}[F(X)]+\delta \cdot \mathbb{E}_{H}[X-F(X)]
$$

subject to

$$
\mathbb{E}_{H}[F(X)]+\delta \cdot \mathbb{E}_{L}[X-F(X)] \leq \mathbb{E}_{L}[X] .
$$

That is, contract $\left(F_{H}, p_{H}\right)$ must maximize the high-type seller's payoff subject to satisfying the low-type seller's incentive compatibility. First, the solution to the above problem is a debt contract, i.e., $F_{H}(X)=\min \left\{d^{E}, X\right\}$ for some $d^{E} \in(0, \bar{X})$ such that $(16)$ holds with equality (see Lemma A.1). Second, suppose that this contract were not offered in equilibrium. But then, there would be a profitable deviation for a buyer to offer contract $\left(F_{H}, p_{H}-\varepsilon\right)$, which would be accepted by the high-type but not by the low-type for $\varepsilon$ small enough. Hence, if a separating equilibrium exists, then it must feature contracts as in the statement of the proposition. By construction of this candidate equilibrium, there are no profitable deviations for buyers that involve them posting separating contracts. We are therefore left to check that there are no deviations involving pooling contracts. Recall that the pooling contract that is most attractive to the high-type and breaks even for the buyers is $\left(F_{\mu_{0}}, p_{\mu_{0}}\right)$ with $F_{\mu_{0}}(X)=\min \left\{d^{*}, X\right\}$ where $d^{*}$ is given by (14) and $p_{\mu_{0}}=\mathbb{E}_{\mu_{0}}\left[F_{\mu_{0}}(X)\right]$. Thus, for a buyer to be able to profitably attract the high-type, it must be that:

$$
\mathbb{E}_{\mu_{0}}\left[\min \left\{d^{*}, X\right\}\right]+\delta \cdot \mathbb{E}_{H}\left[X-\min \left\{d^{*}, X\right\}\right]>\mathbb{E}_{H}\left[\min \left\{d^{E}, X\right\}\right]+\delta \cdot \mathbb{E}_{H}\left[X-\min \left\{d^{E}, X\right\}\right],
$$

in which case a buyer can attract both types with $\left(F_{\mu_{0}}, p_{\mu_{0}}-\varepsilon\right)$ for $\varepsilon$ small enough. But, because the left hand side is increasing in $\mu_{0}$, starting below the right hand side and ending above it, we have that there are no profitable deviations for the buyers if and only if $\mu_{0} \leq \widetilde{\mu}$, where $\widetilde{\mu}$ is such that the inequality (17) holds with equality instead.

Proof of Lemma 1. We first show that each buyer must make zero expected profits in equilibrium. It is clear that each buyer must make non-negative expected profits. Let $\Pi$ denote the aggregate profits of the buyers and suppose to the contrary that $\Pi>0$, and consider buyer $i$ whose expected profits are less than $\frac{\Pi}{2}$. Let $\mathcal{F}_{\theta}$ denote the collection of contracts that are only accepted by the $\theta$-type seller, and let $\mathcal{F}_{\mu_{0}}$ denote the collection that is accepted by both types. Further, consider the contracts $\left\{\left(F_{j}, p_{j}\right)\right\}_{j=H, L, \mu_{0}}$ defined by $p_{j}=\sum_{(F, p) \in \mathcal{F}_{j}} p$ and $F_{j}(X)=\sum_{(F, p) \in \mathcal{F}_{j}} F(X)$ for $j \in\left\{H, L, \mu_{0}\right\}$.

If $p_{\mu_{0}}<\mathbb{E}_{\mu_{0}}\left\{F_{\mu_{0}}(X)\right\}$, then consider a deviation by buyer $i$ to add contract $\left(F_{\mu_{0}}, p_{\mu_{0}}+\varepsilon\right)$ to his menu. Clearly, such a contract will be accepted by both types, instead of the collection $\mathcal{F}_{\mu_{0}}$. Moreover, such a deviation must be profitable for $\varepsilon$ small enough.

If $p_{\mu_{0}} \geq \mathbb{E}_{\mu_{0}}\left\{F_{\mu_{0}}(X)\right\}$, then consider a deviation by buyer $i$ to add contracts $\left(F_{H}, p_{H}+\varepsilon\right)$ and $\left(F_{L}, p_{L}+\varepsilon\right)$ to his menu. Clearly, these contracts will be accepted by the $H$ - and $L$ type respectively, instead of the collections $\mathcal{F}_{H}$ and $\mathcal{F}_{L}$. Moreover, such a deviation must be profitable for $\varepsilon$ small enough: these contracts must be profitable in expectation, since the pooling contracts are not.

We next show that there cannot be cross-subsidization in equilibrium, i.e., it cannot be that 
buyers earn positive expected profits on some contracts and negative expected profits on others. We prove this result in three steps.

Step 1. Let $\left(F_{\mu_{0}}, p_{\mu_{0}}\right)$ denote a contract that is accepted by both types in equilibrium, then it must be that $p_{\mu_{0}}=\mathbb{E}_{\mu_{0}}\left\{F_{\mu_{0}}(X)\right\}$. To see this, let $\left(F_{\mu_{0}}, p_{\mu_{0}}\right)$ be a contract that is accepted by both types in equilibrium. First, suppose that $p_{\mu_{0}}<\mathbb{E}_{\mu_{0}}\left\{F_{\mu_{0}}(X)\right\}$, and that in equilibrium buyer $i$ offers this contract in his menu. Then there is a profitable deviation for buyer $j$ to add contract $\left(F_{\mu_{0}}, p_{\mu_{0}}+\varepsilon\right)$ to his menu, which will be accepted by both types instead of contract $\left(F_{\mu_{0}}, p_{\mu_{0}}\right)$ and, for $\varepsilon$ small, it strictly increases the expected profits of buyer $j$. Second, suppose that $p_{\mu_{0}}>\mathbb{E}_{\mu_{0}}\left\{F_{\mu_{0}}(X)\right\}$, and that in equilibrium buyer $i$ offers this contract. Then there is a profitable deviation for buyer $i$ to withdraw this contrast (as well as other non-trivial contracts that were not accepted in equilibrium) from his menu.

Step 2. Let $\left(F_{\theta}, p_{\theta}\right)$ denote a contract that is accepted only by $\theta$-type seller in equilibrium, then it must be that $p_{H} \leq \mathbb{E}_{H}\left\{F_{H}(X)\right\}$ and $p_{L} \geq \mathbb{E}_{L}\left\{F_{L}(X)\right\}$. Suppose not, and that in equilibrium buyer $i$ offers contract $\left(F_{H}, p_{H}\right)$ in his menu with $p_{H}>\mathbb{E}_{H}\left\{F_{H}(X)\right\}$. Then there is a profitable deviation for buyer $i$ to simply withdraw $\left(F_{H}, p_{H}\right)$, together with other non-trivial contracts that he was offering but that were not accepted in equilibrium, from his menu.

Step 3. Finally, we show that there does not exist an equilibrium in which buyer $i$ offers contracts $\left(F_{H}^{i}, p_{H}^{i}\right)$ and $\left(F_{L}^{i}, p_{L}^{i}\right)$ with $p_{H}^{i}<\mathbb{E}_{H}\left\{F_{H}^{i}(X)\right\}$ and $p_{L}^{i}>\mathbb{E}_{L}\left\{F_{L}^{i}(X)\right\}$, which are accepted by the high- and the low-type respectively. Suppose to the contrary that such contracts were offered by buyer $i$. First, it must be that every buyer $j \neq i$ also includes contracts $\left(F_{H}^{i}, p_{H}^{i}\right)$ in his menu; otherwise, a buyer who does not include it could do so and increase his profits. Second, it must also be that no buyer $j \neq i$ offers contract $\left(F_{L}^{i}, p_{L}^{i}\right)$; otherwise, one of the buyers who offers it could withdraw it from his menu and increase his profits. Lastly, suppose that buyer $i$ were to deviate and include the contracts $\left(F_{L}^{i}, p_{L}^{i}+\varepsilon\right)$ and $\left(F_{H}^{i}, p_{H}^{i}+\varepsilon\right)$ in his menu. Since the low-type weakly prefers contracts $\left\{\left(F_{L}^{j}, p_{L}^{j}\right)\right\}_{i}$ to $\left(F_{H}^{i}, p_{H}^{i}\right)$, she must also weakly prefer contracts $\left\{\left(F_{L}^{j}, p_{L}^{j}\right)\right\}_{j \neq i} \cup\left(F_{L}^{i}, p_{L}^{i}+\varepsilon\right)$ to $\left(F_{H}^{i}, p_{H}^{i}+\varepsilon\right)$. Moreover, the high-type now accepts the contract $\left(F_{H}^{i}, p_{H}^{i}+\varepsilon\right)$ with probability one, whereas contract $\left(F_{H}^{i}, p_{H}^{i}\right)$ was accepted with probability less than one since it was offered by all buyers. Hence, since buyer $i$ was making zero expected profits before, such a deviation is profitable for $\varepsilon$ small enough.

Proof of Proposition 3. Suppose to the contrary that in equilibrium there exists a nontrivial contract $\left(F_{H}, p_{H}\right)$ that is accepted only by the high-type. Let also $\left(F_{L}, p_{L}\right)$ and $\left(F_{\mu_{0}}, p_{\mu_{0}}\right)$ denote respectively the (possibly trivial) contracts that are respectively accepted by the lowtype only and by both types. Suppose without loss that there is at most one contract of each type 20 By Lemma 1, it must be that $p_{\theta}=\mathbb{E}\left\{F_{\theta}(X)\right\}$ and $p_{\mu_{0}}=\mathbb{E}\left\{F_{\mu_{0}}(X)\right\}$. Suppose that buyer $i$ were posting contract $\left(F_{H}, p_{H}\right)$ and buyer $k$ were posting contract $\left(F_{\mu_{0}}, p_{\mu_{0}}\right)$, and consider a deviation by buyer $j \neq i, k$ to withdraw contract $\left(F_{H}, p_{H}\right)$ (if he were also posting it) and instead post contract $(\widetilde{F}, \widetilde{p})$ with $\widetilde{F}(X)=X-F_{\mu_{0}}(X)-F_{H}(X)$ and $\widetilde{p}=\mathbb{E}_{L}\{\widetilde{F}(X)\}-\varepsilon$; observe that $\widetilde{F}(\cdot)$ is monotonic by feasibility of collection $\left\{F_{\mu_{0}}, F_{H}\right\}$, since it is accepted by the high-type. This deviation is clearly profitable for buyer $j$ if the low-type were to accept $(\widetilde{F}, \widetilde{p})$. But the latter follows, since for $\varepsilon$ small enough the low-type's payoff from accepting the

\footnotetext{
${ }^{20}$ If there are multiple contracts of each type, we can simply aggregate them.
} 
contracts $(\widetilde{F}, \widetilde{p}),\left(F_{\mu_{0}}, p_{\mu_{0}}\right)$ and $\left(F_{H}, p_{H}\right)$ from buyers $j, k$ and $i$ respectively satisfies:

$$
\begin{aligned}
\tilde{p}+p_{\mu_{0}}+p_{H} & =\mathbb{E}_{L}\{\widetilde{F}(X)\}-\varepsilon+\mathbb{E}_{\mu_{0}}\left\{F_{\mu_{0}}(X)\right\}+\mathbb{E}_{H}\left\{F_{H}(X)\right\} \\
& >\mathbb{E}_{L}\{\widetilde{F}(X)\}+\mathbb{E}_{\mu_{0}}\left\{F_{\mu_{0}}(X)\right\}+\mathbb{E}_{L}\left\{F_{H}(X)\right\} \\
& =\mathbb{E}_{L}\left\{X-F_{\mu_{0}}(X)\right\}+\mathbb{E}_{\mu_{0}}\left\{F_{\mu_{0}}(X)\right\} \\
& \geq \mathbb{E}_{L}\left\{F_{L}(X)\right\}+\mathbb{E}_{\mu_{0}}\left\{F_{\mu_{0}}(X)\right\}
\end{aligned}
$$

where the first inequality follows by monotonicity of $F_{H}$, and the last inequality follows from feasibility: $F_{L}(x)+F_{\mu_{0}}(x) \leq x$ for all $x \in[0, \bar{X}]$. But, note that the last expression is just the low-type's equilibrium payoff.

Proof of Proposition 4. Given Lemma 1 and Proposition 3, any contract $(F, p)$ that is accepted by the $H$-type seller must be priced at average valuation $p=\mathbb{E}_{\mu_{0}}\{F(X)\}$. Among all such contracts, the security that maximizes the $H$-type's payoff solves the following problem:

$$
F^{*}=\arg \max _{F \in \Delta} \mathbb{E}_{\mu_{0}}\{F(X)\}+\delta \cdot \mathbb{E}_{H}\{X-F(X)\}
$$

If such a security exists, then in equilibrium it must be offered by at least one buyer and accepted by the $H$-type seller. Otherwise, there is a profitable deviation for a buyer to offer security $F^{*}$ at price slightly below $\mathbb{E}_{\mu_{0}}\left\{F^{*}(X)\right\}$ and attract the $H$-type and, possibly, the $L$-type seller.

Next, suppose that the security $F^{*}$ that solves the problem in (19) exists, but that it is not a debt contract, i.e. $\nexists d \in[0, \bar{X}]$ such that $F^{*}(X)=\min \{d, X\}$. Now, consider security $\min \{d, X\}$ with debt level $d \in[0, \bar{X}]$ satisfying $\mathbb{E}_{\mu_{0}}\{\min \{d, X\}\}=\mathbb{E}_{\mu_{0}}\left\{F^{*}(X)\right\}$. By continuity, such a $d$ exists. As $F^{*}(\cdot)$ is monotonic and not a debt contact, there exists an $\widetilde{x} \in(0, \bar{X})$ such that $\min \{d, x\}<F^{*}(x)$ if and only if $x>\widetilde{x}$, with strict inequality on a set of positive measure. But then, by the MLRP, we have that $\mathbb{E}_{H}\left\{F^{*}(X)\right\}>\mathbb{E}_{H}\{\min \{d, X\}\}$, since both securities have the same average valuation:

$$
\begin{aligned}
\mathbb{E}_{H}\left[F^{*}(X)-\min \{d, X\}\right] & =\mathbb{E}_{\mu_{0}}\left[\left(F^{*}(X)-\min \{d, X\}\right) \cdot \frac{g_{H}(X)}{g_{\mu_{0}}(X)}\right] \\
& >\mathbb{E}_{\mu_{0}}\left[F^{*}(X)-\min \{d, X\}\right] \cdot \frac{g_{H}(\widetilde{x})}{g_{\mu_{0}}(\widetilde{x})}=0
\end{aligned}
$$

where $g_{\mu_{0}} \equiv \mu_{0} \cdot g_{H}+\left(1-\mu_{0}\right) \cdot g_{L}$. This in turn implies that:

$$
\mathbb{E}_{\mu_{0}}\{\min \{d, X\}\}-\delta \cdot \mathbb{E}_{H}\{\min \{d, X\}\}>\mathbb{E}_{\mu_{0}}\left\{F^{*}(X)\right\}-\delta \cdot \mathbb{E}_{H}\left\{F^{*}(X)\right\},
$$

a contradiction. Thus, if a solution to the problem in 19 exists, it must be a debt contract. Since the objective is differentiable (and thus continuous), a maximizer $d^{*}$ exists. Moreover, the derivative of the objective w.r.t. $d$ is given by $1-\mu_{0} \cdot G_{H}(d)-\left(1-\mu_{0}\right) \cdot G_{L}(d)-\delta \cdot\left(1-G_{H}(d)\right)$. This expression is positive for $d$ small enough, so $d^{N E}>0$; and it is equal to zero at interior value of $d$ if and only if $\mu_{0}<\frac{\lim _{x \rightarrow \bar{X}} \delta \cdot \frac{g_{H}(x)}{g_{L}(x)}-1}{\lim _{x \rightarrow \bar{X}} \frac{g_{H}(x)}{g_{L}(x)}-1} \equiv \bar{\mu}$; so $d^{N E}<\bar{X}$ if and only if $\mu_{0}<\bar{\mu}$.

Proof of Proposition 5. Suppose to the contrary that the $L$-type seller does not issue all of her cash flows. Let these remaining cash flows be denoted by $F(X)$, which is positive on a 
set of positive measure and is monotonic by feasibility. These cash flows thus give the seller a payoff $\delta \cdot \mathbb{E}_{L}[F(X)]<\mathbb{E}_{L}[F(X)]$. Consider now a deviation for a buyer to add contract $(F, p)$ to his menu, where $p=\mathbb{E}_{L}\{F(X)\}-\varepsilon$. Since the addition of contract $(F, p)$ does not affect the relative attractiveness of other contracts to the seller, the contract $(F, p)$ will be accepted by the $L$-type seller for $\varepsilon$ small and, thus, the deviation must be profitable for the buyer.

Proof of Proposition 6. Consider the following candidate equilibrium. All buyers post the contracts $\left(F_{S}, p_{S}\right)$ and $\left(F_{J}, p_{J}\right)$ that are accepted with positive probability by the seller, and the following sets of latent contracts $\mathcal{L}_{\mu_{0}}$ and $\mathcal{L}_{L}$, which we define next:

1. Latent contracts priced at average valuation:

$$
\mathcal{L}_{\mu_{0}} \equiv\left\{(F, p): \exists(\widetilde{F}, \widetilde{p}) \in \Omega \text { s.t. } F(X)=\min \left\{d^{N E}-\widetilde{F}\left(d^{N E}\right), X-\widetilde{F}(X)\right\} \& p=\mathbb{E}_{\mu_{0}}\{F(X)\}\right\},
$$

2. Latent contracts priced at low valuation:

$\mathcal{L}_{L} \equiv\left\{(F, p): \exists(\widetilde{F}, \widetilde{p}) \in \Omega\right.$ s.t. $\left.F(X)=X-\widetilde{F}(X)-\min \left\{d^{N E}-\widetilde{F}\left(d^{N E}\right), X-\widetilde{F}(X)\right\} \& p=\mathbb{E}_{L}\{F(X)\}\right\}$,

where the set $\Omega$ consists of all contracts $(\widetilde{F}, \widetilde{p})$ such that:

$$
\begin{aligned}
\widetilde{p}+\delta \cdot \mathbb{E}_{H}\{X-\widetilde{F}\} & \geq u_{H}^{N E}, \\
\widetilde{p}+\mathbb{E}_{L}\{X-\widetilde{F}\} & \leq u_{L}^{N E},
\end{aligned}
$$

and such that $\widetilde{F}(X)$ and $X-\widetilde{F}(X)$ are monotonic, and $\widetilde{p} \in\left[\mathbb{E}_{\mu_{0}}\{\widetilde{F}(X)\}, \mathbb{E}_{H}\{\widetilde{F}(X)\}\right]$, where recall that $u_{\theta}^{N E}$ is the candidate equilibrium payoff of the $\theta$-type seller.

We now show that there are no profitable deviations for the seller or the buyers, i.e., the $H$-type only accepts contract $\left(F_{S}, p_{S}\right)$, the $L$-type only accepts contracts $\left(F_{S}, p_{S}\right)$ and $\left(F_{J}, p_{J}\right)$ (from two different buyers), and no buyer wants to deviate to a different menu of contracts.

Step 1. We show that there are no profitable deviations for the seller.

First, observe that it is not feasible for the seller to issue any non-trivial latent contract from the set $\mathcal{L}_{\mu_{0}}$ in addition to the equilibrium contract $\left(F_{S}, p_{S}\right)$, since any non-trivial latent contract in $\mathcal{L}_{\mu_{0}}$ must have $d^{N E}>\widetilde{F}\left(d^{N E}\right)$ for some $(\widetilde{F}, \widetilde{p}) \in \Omega$, which implies that:

$$
\left.\left(F_{S}(x)+\min \left\{d^{N E}-\widetilde{F}\left(d^{N E}\right), x-\widetilde{F}(x)\right\}\right)\right|_{x=d^{N E}}>F_{S}\left(d^{N E}\right)=d^{N E},
$$

violating feasibility.

Second, the seller would also not want to accept a collection $\left\{\left(F_{i}, p_{i}\right)\right\}$ of latent contracts instead of the equilibrium contract $\left(F_{S}, p_{S}\right)$. To see this, first note that by construction the cash flows $F_{S}$ issued by the $H$-type seller maximize her payoff, conditional on being priced at average valuation (see (5)). Thus, $H$-type weakly prefers to accept $\left(F_{S}, p_{S}\right)$ to any collection of latent contracts, since latent contracts are priced either at average or low valuation. As for the $L$-type, suppose that she were to issue the collection $\left\{\left(F_{i}, p_{i}\right)\right\}$ from the set $\mathcal{L}_{\mu_{0}}$ plus possibly the residual cash flows using a latent contract in $\mathcal{L}_{L}$ instead of the equilibrium contracts $\left(F_{S}, p_{S}\right)$ and $\left(F_{J}, p_{J}\right)$. For this deviation to be attractive to the $L$-type, it must be that $\sum_{i} \min \left\{d^{N E}-\right.$ $\left.\widetilde{F}_{i}\left(d^{N E}\right), x-\widetilde{F}_{i}(x)\right\}>F_{S}\left(d^{N E}\right)=\min \left\{d^{N E}, x\right\}$ for some $x>d^{N E}$. However, if $x \leq d^{N E}$, 
feasibility implies that:

$$
\sum_{i} \min \left\{d^{N E}-\widetilde{F}_{i}\left(d^{N E}\right), x-\widetilde{F}_{i}(x)\right\}=\sum_{i}\left(x-\widetilde{F}_{i}(x)\right) \leq x=F_{S}(x),
$$

which in turn implies that whenever $x>d^{N E}$, then:

$$
\sum_{i} \min \left\{d^{N E}-\widetilde{F}_{i}\left(d^{N E}\right), x-\widetilde{F}_{i}(x)\right\} \leq \sum_{i}\left(d^{N E}-\widetilde{F}_{i}\left(d^{N E}\right)\right) \leq d^{N E}=F_{S}(x) .
$$

Thus, such a deviation is not attractive to the $L$-type. It is also straightforward that the $L$-type weakly prefers to accept equilibrium contracts to any latent contract from $\mathcal{L}_{L}$.

Step 2. We next show that there are no profitable deviations for the buyers.

By construction there does not exist a profitable deviation which attracts both types or just the $L$-type. Thus, we need to rule out a profitable deviation that attracts only the $H$ type. Any such deviation would consist of a contract $(\widetilde{F}, \widetilde{p}) \in \Omega$ with $\widetilde{p}>\mathbb{E}_{\mu_{0}}\{\widetilde{F}(X)\}$, since the $H$-type must be strictly better off than accepting contract $\left(F_{S}, p_{S}\right)$. But, note that if it were offered, contract $(\widetilde{F}, \widetilde{p})$ would also be accepted by the $L$-type, since she would then also accept the corresponding latent contracts $\left(F_{1}, p_{1}\right) \in \mathcal{L}_{\mu_{0}}$ and $\left(F_{2}, p_{2}\right) \in \mathcal{L}_{L}$ with $F_{1}(X)=$ $\min \left\{d^{N E}-\widetilde{F}\left(d^{N E}\right), X-\widetilde{F}(X)\right\}$ and $F_{2}(X)=X-\widetilde{F}(X)-\min \left\{d^{N E}-\widetilde{F}\left(d^{N E}\right), X-\widetilde{F}(X)\right\}$, which together yield her a higher payoff than her equilibrium contracts:

$$
\begin{aligned}
\widetilde{p}+\mathbb{E}_{\mu_{0}}\left\{F_{1}(X)\right\}+\mathbb{E}_{L}\left\{F_{2}(X)\right\} & >\mathbb{E}_{\mu_{0}}\left\{\widetilde{F}(X)+F_{1}(X)\right\}+\mathbb{E}_{L}\left\{X-\widetilde{F}(X)-F_{1}(X)\right\} \\
& \geq \mathbb{E}_{\mu_{0}}\left\{F_{S}(X)\right\}+\mathbb{E}_{L}\left\{X-F_{S}(X)\right\}
\end{aligned}
$$

where the last inequality follows from the fact that $\widetilde{F}(X)+F_{1}(X) \geq F_{S}(X)$ as: (i) $\widetilde{F}(X)+$ $F_{1}(X)=X=F_{S}(X)$ if $X \leq d^{N E}$, and (ii) $\widetilde{F}(X)+F_{1}(X)=\widetilde{F}(X)+d^{N E}-\widetilde{F}\left(d^{N E}\right) \geq d^{N E}=$ $F_{S}(X)$ otherwise.

Proof of Proposition 7. Under both exclusive and non-exclusive market structures, the buyers break even. So the entire trading surplus accrues to the seller.

When markets are non-exclusive, the expected trading surplus (i.e., the expected welfare of the seller) is given by:

$$
W^{N E}\left(\mu_{0}\right) \equiv \mathbb{E}_{\mu_{0}}\{X\}-\mu_{0} \cdot(1-\delta) \cdot \mathbb{E}_{H}\left\{X-\min \left\{d^{N E}\left(\mu_{0}\right), X\right\}\right\},
$$

where $d^{N E}\left(\mu_{0}\right)<\bar{X}$ if and only if $\mu_{0}<\bar{\mu} \in(0,1)$ (see definition of $\bar{\mu}$ in proof of Proposition 44, in which case $d^{N E}\left(\mu_{0}\right)$ is defined by the first order condition:

$$
1-\mu_{0} \cdot G_{H}\left(d^{N E}\right)-\left(1-\mu_{0}\right) \cdot G_{L}\left(d^{N E}\right)=\delta \cdot\left(1-G_{H}\left(d^{N E}\right)\right) .
$$

Thus, $d^{N E}(\cdot)$ is continuous and increasing, with the property that $d^{N E}(0)>0$ and it goes to $\bar{X}$ as $\mu_{0}$ goes to $\bar{\mu}$.

Instead, the expected trading surplus with exclusive markets is given by:

$$
W^{E}\left(\mu_{0}\right) \equiv \mathbb{E}_{\mu_{0}}\{X\}-\mu_{0} \cdot(1-\delta) \cdot \mathbb{E}_{H}\left\{X-\min \left\{d^{E}, X\right\}\right\},
$$


where $d^{E} \in(0, \bar{X})$ is independent of $\mu_{0}$. Moreover, an equilibrium with exclusive markets exists if and only if $\mu_{0} \leq \widetilde{\mu} \in(0,1)$ (see Proposition 2).

We now show that there exists a $\mu^{*} \in(0, \widetilde{\mu})$ such that the expected trading surplus with non-exclusive markets is greater than with exclusive markets if $\mu_{0} \in\left(\mu^{*}, \widetilde{\mu}\right)$, the two coincide if $\mu_{0}=\mu^{*}$, and the expected trading surplus with exclusive markets is greater if $\mu_{0} \in\left(0, \mu^{*}\right)$. To this end, note that:

$$
W^{N E}\left(\mu_{0}\right)-W^{E}\left(\mu_{0}\right)=\mu_{0} \cdot(1-\delta) \cdot\left(\mathbb{E}_{H}\left\{\min \left\{d^{N E}\left(\mu_{0}\right), X\right\}\right\}-\mathbb{E}_{H}\left\{\min \left\{d^{E}, X\right\}\right\}\right),
$$

which is continuous and increasing in $\mu_{0}$ on $[0, \widetilde{\mu}]$. Furthermore, $\widetilde{\mu}$ is defined by:

$$
\begin{aligned}
(1-\delta) \cdot \mathbb{E}_{H}\left\{\min \left\{d^{E}, X\right\}\right\} & =\mathbb{E}_{\widetilde{\mu}}\left\{\min \left\{d^{N E}(\widetilde{\mu}), X\right\}\right\}-\delta \cdot \mathbb{E}_{H}\left\{\min \left\{d^{N E}(\widetilde{\mu}), X\right\}\right\} \\
& <(1-\delta) \cdot \mathbb{E}_{H}\left\{\min \left\{d^{N E}(\widetilde{\mu}), X\right\}\right\}
\end{aligned}
$$

which implies that $d^{N E}(\widetilde{\mu})>d^{E}$ and, thus, $W^{N E}(\widetilde{\mu})>W^{E}(\widetilde{\mu})$. This proves that $\mu^{*}<\widetilde{\mu}$. Next, in non-exclusive markets, when $\mu_{0}$ goes to zero, the $H$-type issues the security $d^{N E}\left(\mu_{0}\right)$ essentially at low valuation. However, in exclusive markets, she strictly prefers not to issue any additional cashflows (i.e. more than $d^{E}$ ) at low valuation. By continuity, this implies that $d^{N E}\left(\mu_{0}\right)<d^{E}$ and, thus, $W^{N E}\left(\mu_{0}\right)<W^{E}\left(\mu_{0}\right)$ if $\mu_{0}$ is small. This proves that $\mu^{*} \in(0, \widetilde{\mu})$.

Proof of Proposition 8. Consider first exclusive markets. The payoffs of the seller in the equilibrium of the trading stage for a given $\mu_{0}$ are:

$$
\begin{aligned}
u_{L}^{E} & =\mathbb{E}_{L}[X] \\
u_{H}^{E} & =\mathbb{E}_{H}[X]-(1-\delta) \cdot \mathbb{E}_{H}\left[\max \left\{X-d^{E}, 0\right\}\right] .
\end{aligned}
$$

These payoffs are independent of $\mu_{0}$, since $d^{E}$ is independent of $\mu_{0}$. In addition, note that $u_{L}^{E}=u_{L}^{F B}$ and $u_{L}^{E}<u_{H}^{E}<u_{H}^{F B}$ since $d^{E} \in(0, \bar{X})$. Thus, the (unique) equilibrium average asset quality with exclusive markets, given by $\mu_{0}^{E}=c^{\prime-1}\left(u_{H}^{E}-u_{L}^{E}\right)$, is interior and strictly below the unique average asset quality at first-best, which is $\mu_{0}^{F B}=c^{\prime-1}\left(u_{H}^{F B}-u_{L}^{F B}\right)$. Moreover, an equilibrium with exclusive markets exists if and only if $\mu_{0}^{E} \leq \widetilde{\mu}$, which is equivalent to requiring that the cost function satisfy: $c^{\prime}(\widetilde{\mu}) \geq u_{H}^{E}-u_{L}^{E}$.

Consider next non-exclusive markets. The payoffs of the seller in the equilibrium of the trading stage for a given $\mu_{0}$ are:

$$
\begin{aligned}
& u_{L}^{N E}=\mathbb{E}_{L}[X]+\Delta\left(\mu_{0}\right), \\
& u_{H}^{N E}=\mathbb{E}_{H}[X]-(1-\delta) \cdot \mathbb{E}_{H}\left[\max \left\{X-d^{N E}\left(\mu_{0}\right), 0\right\}\right]-\frac{1-\mu_{0}}{\mu_{0}} \cdot \Delta^{N E}\left(\mu_{0}\right),
\end{aligned}
$$

where $\Delta^{N E}\left(\mu_{0}\right)=\mathbb{E}_{\mu_{0}}\left[\min \left\{d^{N E}\left(\mu_{0}\right), X\right\}\right]-\mathbb{E}_{L}\left[\min \left\{d^{N E}\left(\mu_{0}\right), X\right\}\right]$. These payoffs thus depend on $\mu_{0}$ both through $d^{N E}\left(\mu_{0}\right)$ and through $\Delta\left(\mu_{0}\right)$. Moreover, it is easy to show that the payoff gap $u_{H}^{N E}\left(\mu_{0}\right)-u_{L}^{N E}\left(\mu_{0}\right)$ is decreasing in $\mu_{0}$ and is equal to 0 when $\mu_{0}=\bar{\mu}$ since then $d^{N E}\left(\mu_{0}\right)=\bar{X}$ (see definition of $\bar{\mu}$ in proof of Proposition 4). Thus, it follows that the (unique) equilibrium average asset quality, denoted by $\mu_{0}^{N E}$, is interior and satisfies $\mu_{0}^{N E} \in(0, \bar{\mu})$.

We now show that $\mu_{0}^{N E}<\mu_{0}^{E}$, for which it suffices to show that the payoff gaps are ranked as follows: $u_{H}^{N E}\left(\mu_{0}\right)-u_{L}^{N E}\left(\mu_{0}\right)<u_{H}^{E}-u_{L}^{E}$ for all $\mu_{0} \in(0, \widetilde{\mu})$. First, note that $u_{L}^{N E}\left(\mu_{0}\right)>u_{L}^{E}$ 
for any $\mu_{0}>0$ since $\Delta^{N E}\left(\mu_{0}\right)>0$. Second, it must be that $u_{H}^{N E}\left(\mu_{0}\right) \leq u_{H}^{E}$ for any $\mu_{0} \leq \widetilde{\mu}$ with strict inequality if $\mu_{0}<\widetilde{\mu}$. The latter follows from the simple observation that (i) $u_{H}^{N E}\left(\mu_{0}\right)$ is increasing in $\mu_{0}$; and (ii) when $\mu_{0}=\widetilde{\mu}$, the $H$-type seller is just indifferent to issuing security $F_{H}(X)=\min \left\{d^{E}, X\right\}$ at high valuation vs. security $F_{S}(X)=\min \left\{d^{N E}\left(\mu_{0}\right), X\right\}$ at average valuation, which implies $u_{H}^{N E}(\widetilde{\mu})=u_{H}^{E}$ (see proof of Proposition 2). This completes the proof of the proposition.

Lemma A.1 The security $F_{H}$ that solves (15) subject to (16) is a debt contract, $F_{H}(X)=$ $\min \left\{d^{E}, X\right\}$, where $d^{E}$ satisfies:

$$
\mathbb{E}_{H}\left[\min \left\{d^{E}, X\right\}\right]+\delta \cdot \mathbb{E}_{L}\left[X-\min \left\{d^{E}, X\right\}\right]=\mathbb{E}_{L}[X]
$$

Proof. Observe that $d^{E}$ satisfying (37) exists by continuity and the fact that $\mathbb{E}_{H}[X]>\mathbb{E}_{L}[X]>$ $\delta \cdot \mathbb{E}_{L}[X]$. Next, let $\left(F_{H}, p_{H}\right)$ denote the contract accepted by the $H$-type in a candidate separating equilibrium; recall that the low-type must accept the equity contract $\left(F_{L}, p_{L}\right)$ with $F_{L}(X)=X$ and $p_{L}=\mathbb{E}_{L}[X]$ (see argument in proof of Proposition 2). Suppose to the contrary that $F_{H}$ is a debt contract, $F_{H}(X)=\min \left\{d^{\prime}, X\right\}$, but that $d^{\prime} \neq d^{E}$. Then, it must be that $d^{\prime}<d^{E}$ and the low-type's incentive compatibility constraint $(16)$ is slack. Consider a deviation for a buyer to include contract $\left(F^{\prime}, p^{\prime}\right)$ with $F^{\prime}(X)=\min \left\{d^{E}, X\right\}$ and $p^{\prime}=\mathbb{E}_{H}\left[F^{\prime}(X)\right]-\varepsilon$ to his menu. Clearly, the low-type prefers to accept the equity contract to contract $\left(F^{\prime}, p^{\prime}\right)$ for any $\varepsilon \geq 0$. But, since $\mathbb{E}_{H}\left[F^{\prime}(X)\right]>\mathbb{E}_{H}\left[F_{H}(X)\right]$, for $\varepsilon$ small enough the high-type must prefer to accept contract $\left(F^{\prime}, p^{\prime}\right)$ to contract $\left(F_{H}, p_{H}\right)$. Hence, such a deviation must be profitable.

Next, suppose to the contrary that $F_{H}$ is not a debt contract, and let $d^{\prime}$ be such that $\mathbb{E}_{H}\left[F_{H}(X)\right]=\mathbb{E}_{H}\left[\min \left\{d^{\prime}, X\right\}\right]$. Since $F_{H}(\cdot)$ is monotonic, there exists $\widehat{x} \in[0, \bar{X}]$ such that $F_{H}(x)>d^{\prime}$ if and only if $x>\widehat{x}$. By MLRP, it must then be that $\mathbb{E}_{L}\left[X-F_{H}(X)\right]>\mathbb{E}_{L}[X-$ $\left.\min \left\{d^{\prime}, X\right\}\right]$, since both securities have the same high valuation:

$$
\begin{aligned}
\mathbb{E}_{L}\left[F_{H}(X)-\min \left\{d^{\prime}, X\right\}\right] & =\mathbb{E}_{H}\left[\left(F_{H}(X)-\min \left\{d^{\prime}, X\right\}\right) \cdot \frac{g_{L}(X)}{g_{H}(X)}\right] \\
& <\mathbb{E}_{H}\left[F_{H}(X)-\min \left\{d^{\prime}, X\right\}\right] \cdot \frac{g_{L}(\widehat{x})}{g_{H}(\widehat{x})}=0
\end{aligned}
$$

Thus, whereas the high-type is indifferent between contracts $\left(F_{H}, p_{H}\right)$ and $\left(F^{\prime}, p_{H}\right)$ with $F^{\prime}(X)=$ $\min \left\{d^{\prime}, X\right\}$, the low-type strictly prefers the equity contract to contract $\left(F^{\prime}, p_{H}\right)$. Consider a deviation for a buyer to include contract $\left(F^{\prime \prime}, p^{\prime \prime}\right)$ with $F^{\prime \prime}(X)=\min \left\{d^{\prime \prime}, X\right\}, p^{\prime \prime}=\mathbb{E}_{H}\left[F^{\prime \prime}(X)\right]-\varepsilon$, and $d^{\prime \prime}>d^{\prime}$ in his menu. If $d^{\prime \prime}$ is close to $d^{\prime}$, then the low-type still prefers to accept the equity contract to contract $\left(F^{\prime \prime}, p^{\prime \prime}\right)$ for any $\varepsilon \geq 0$. But, since $\mathbb{E}_{H}\left[F^{\prime \prime}(X)\right]>\mathbb{E}_{H}\left[F_{H}(X)\right]$, for $\varepsilon$ small enough the high type must prefer contract $\left(F^{\prime \prime}, p^{\prime \prime}\right)$ to contract $\left(F_{H}, p_{H}\right)$. Hence, such a deviation must be profitable. 